\title{
The spectrum of brain malformations and disruptions in twins
}

Kaylee B. Park, ${ }^{1}$ Teresa Chapman, ${ }^{2}$ Kimberly A. Aldinger, ${ }^{3}$ Ghayda M Mirzaa, ${ }^{3-5}$ Jordan Zeiger, ${ }^{3}$ Anita Beck, ${ }^{4}$ Ian A. Glass, ${ }^{4}$ Robert F. Hevner, ${ }^{6}$ Anna C. Jansen, ${ }^{7}$ Desiree A. Marshall, ${ }^{8}$ Renske Oegema, ${ }^{9}$ Elena Parrini, ${ }^{10}$ Russell P. Saneto, ${ }^{11}$ Cynthia J. Curry, ${ }^{12}$ Judith G. Hall, ${ }^{13}$ Renzo Guerrini, ${ }^{10}$ Richard J. Leventer, ${ }^{14}$ William B. Dobyns ${ }^{15}$

\section{AUTHORS and ADDRESSES}

Kaylee B Park <kbpark@uw.edu>

${ }^{1}$ University of Washington School of Medicine, Seattle, WA, 98105;

(UW School of Medicine; 1959 NE Pacific St, Seattle, WA 98195)

Teresa Chapman <teresa.chapman@seattlechildrens.org>

${ }^{2}$ Department of Radiology, University of Washington School of Medicine, Seattle, WA, 98105;

(Seattle Children's Hospital; Department of Radiology, MA.7.220; 4800 Sand Point Way NE; Seattle WA 98105)

Kimberly A Aldinger < kimberly.aldinger@seattlechildrens.org>

${ }^{3}$ Seattle Children's Research Institute, Center for Integrative Brain Research, Seattle, WA 98101;

(Seattle Children's Research Institute; 1900 Ninth Avenue, M/S JMB-10: Seattle WA 98101)

This is the author manuscript accepted for publication and has undergone full peer review but has not been through the copyediting, typesetting, pagination and proofreading process, which may lead to differences between this version and the Version of Record. Please cite this article as doi: 10.1002/ajmg.a.61972

This article is protected by copyright. All rights reserved. 
Ghayda M Mirzaa <gmirzaa@uw.edu>

${ }^{3}$ Seattle Children's Research Institute, Center for Integrative Brain Research, Seattle, WA 98101;

${ }^{4}$ Department of Pediatrics, University of Washington School of Medicine, Seattle, WA 98105; ${ }^{5}$ Brotman Baty Institute for Precision Medicine, Seattle, WA 98195;

(Seattle Children's Research Institute; 1900 Ninth Avenue, M/S JMB-10: Seattle WA 98101)

Jordan Zeiger <jezeiger@gmail.com>

${ }^{3}$ Seattle Children's Research Institute, Center for Integrative Brain Research, Seattle, WA 98101;

(Seattle Children's Research Institute; 1900 Ninth Avenue, M/S JMB-10: Seattle WA 98101)

Anita Beck <aebeck@uw.edu>

${ }^{4}$ Department of Pediatrics, University of Washington School of Medicine, Seattle, WA 98105;

(Seattle Children's Hospital: Division of Medical Genetics, A-7937: 4800 Sand Point Way NE: Seattle WA 98105-0371)

Ian A Glass <ianglass@uw.edu>

${ }^{4}$ Department of Pediatrics, University of Washington School of Medicine, Seattle, WA 98105;

(Seattle Children's Hospital: Division of Medical Genetics, A-7937: 4800 Sand Point Way NE: Seattle WA 98105-0371)

This article is protected by copyright. All rights reserved. 
Robert F. Hevner <rhevner@health.ucsd.edu>

${ }^{6}$ Department of Pathology, University of California San Diego, La Jolla, CA 92093;

(UCSD; Department of Pathology; 9500 Gilman Drive \#0695; La Jolla CA 92093)

7Anna C. Jansen <anna.jansen@uzbrussel.be>

Neurogenetics Research Group, Reproduction Genetics and Regenerative Medicine Research

Cluster, Vrije Universiteit Brussel; and Pediatric Neurology Unit, Universitair Ziekenhuis Brussel,

Brussels, Belgium(Department of Pediatric Neurology, Universitair Ziekenhuis Brussel;

Laarbeeklaan 101 - 1090; Brussel, Belgium)

Desiree A. Marshall <damarsh@uw.edu>

${ }^{8}$ Department of Anatomic Pathology and Neuropathology; University of Washington School of Medicine, Seattle, WA 98105;

(Box 356100/ NE110-B; 1959 NE Pacific Street, Seattle, WA 98195)

Renske Oegema <r.oegema@umcutrecht.nl $>$

'University Medical Center Utrecht, Department of Genetics, Utrecht, The Netherlands

(UMC Utrecht; Division of Biomedical Genetics; Room KC.04.088.2; P.O. Box 85090; Utrecht 3508 AB Utrecht; The Netherlands)

Elena Parrini <elena.parrini@meyer.it>

This article is protected by copyright. All rights reserved. 
${ }^{10}$ Pediatric Neurology, Neurogenetics and Neurobiology Unit and Laboratories, Meyer Children's Hospital, University of Florence, Florence, Italy

(Pediatric Hospital A. Meyer-University of Firenze; Viale Pieraccini 24; 50139 Firenze; Italy)

Russel P. Saneto <russ.saneto@seattlechildrens.org>

${ }^{11}$ Department of Neurology, University of Washington School of Medicine, Seattle, WA 98105;

(Seattle Children's Hospital; Neurology, B-5552; 4800 Sand Point Way NE; Seattle WA 98105)

Cynthia J. Curry <cynthia.curry@gmail.com>

${ }^{12}$ Genetic Medicine, Department of Pediatrics, University of California San Francisco, Fresno, CA 93701;

(Genetic Medicine, 215 N Fresno Street \#300, Fresno, Ca 93701)

Judith G. Hall <jhall@cw.bc.ca>

${ }^{13}$ Departments of Medical Genetics and Pediatrics, University of British Columbia and BC Children's Hospital, Vancouver, Canada;

(BC Children's Hospital, 4500 Oak Street, Room C234, Vancouver, BC, Canada V6H 3N1)

Renzo Guerrini <r.guerrini@meyer.it>

${ }^{10}$ Pediatric Neurology, Neurogenetics and Neurobiology Unit and Laboratories, Meyer Children's Hospital, University of Florence, Florence, Italy

(Pediatric Hospital A. Meyer-University of Firenze; Viale Pieraccini 24; 50139 Firenze; Italy)

This article is protected by copyright. All rights reserved. 
Richard J Leventer <richard.leventer@rch.org.au>

${ }^{14}$ Department of Neurology Royal Children's Hospital, Murdoch Children's Research Institute and University of Melbourne Department of Pediatrics, Melbourne, Australia 3052.

(The Royal Children's Hospital Melbourne; 50 Flemington Road; Parkville Victoria 3052;

Australia)

William B. Dobyns <wbdobyns@umn.edu>

${ }^{15}$ Department of Pediatrics, Division of Genetics and Metabolism, University of Minnesota, Minneapolis, MN;

(University of Minnesota, Department of Pediatrics (Genetics); 420 Delaware Street, MMC75; Minneapolis, MN 55455)

Correspondence:

William B. Dobyns, MD

University of Minnesota

Department of Pediatrics (Genetics)

420 Delaware Street, MMC75

Minneapolis, MN 55455

This article is protected by copyright. All rights reserved. 
ABSTRACT $(W=220)$

Twins have an increased risk for congenital malformations and disruptions, including defects in brain morphogenesis. We analyzed data on brain imaging, zygosity, sex and fetal demise in 56 proband twins and 7 less affected co-twins with abnormal brain imaging and compared them to population-based data and to a literature series. We separated our series into malformations of cortical development (MCD, $N=39)$, cerebellar malformations without $M C D(N=13)$, and brain disruptions (N=11). The MCD group included $37 / 39$ (95\%) with polymicrogyria (PMG), 8/39 (21\%) with pia-ependymal clefts (schizencephaly), and 15/39 (38\%) with periventricular nodular heterotopia $(\mathrm{PNH})$ including 2 with $\mathrm{PNH}$ but not PMG. Cerebellar malformations were found in 19 individuals including 13 with a cerebellar malformation only and another 6 with cerebellar malformation and MCD. The pattern varied from diffuse cerebellar hypoplasia (CBLH) to classic Dandy-Walker malformation (DWM). Brain disruptions were seen in 11 individuals with hydranencephaly, porencephaly or white matter loss without cysts.

Our series included an expected statistically significant excess of monozygotic (MZ) twin pairs (22/41 MZ, 54\%) compared to population data (482/1448 MZ, 33.3\%; $\mathrm{P}=.0110)$, and an unexpected statistically significant excess of dizygotic (DZ) twins (19/41, 46\%) compared to the literature cohort $(1 / 46 \mathrm{DZ}, 2 \% ; P<0.0001$. Recurrent association with twin-twin transfusion syndrome, intrauterine growth retardation, and other prenatal factors support disruption of vascular perfusion as the most likely unifying cause.

This article is protected by copyright. All rights reserved. 


\section{KEY WORDS}

Cerebellar hypoplasia, Dandy-Walker malformation, hydranencephaly, malformations of cortical development, polymicrogyria, periventricular nodular heterotopia, porencephaly, sex ratio, subcortical malformations, twins, twinning, zygosity, dizygotic twins, monozygotic twins

\section{RUNNING TITLE}

Brain malformations in twins

This article is protected by copyright. All rights reserved. 


\section{INTRODUCTION}

Twins and higher order multiple births have an increased risk for congenital malformations, disruptions, and deformations that is higher for monochorionic than dichorionic twins. Risks for both monochorionic and dichorionic twins are higher than those observed in singletons [Dawson et al., 2016; Glinianaia et al., 2008; Myrianthopoulos, 1976; Spranger et al., 1982]. Similarly, monochorionic twins have an increased risk for less specific neurodevelopmental disorders compared to dichorionic twins [Adegbite et al., 2005 Livinec, 2005 \#18263; Luu and Vohr, 2009]. As almost all monochorionic twins are monozygotic (MZ) and most ( $90 \%)$ dichorionic twins are dizygotic (DZ), these data imply that the risks for congenital malformations, disruptions, and less specific neurodevelopmental problems are higher in MZ than DZ twins. Remarkably, sex has rarely been examined as a variable factor for developmental outcome, even in large epidemiological studies of twins.

The increased rate of malformations and disruptions observed in twins has been attributed to several factors with variable support. Early defects in morphogenesis such as conjoined twins and neural tube defects have been attributed to complications of the twinning process itself with weak support [Schinzel et al., 1979]. Several twinning-associated syndromes such as LBWC, MURCS, OAVS, OEIS, POC and VACTERL (see list of abbreviations) appear to have early embryonic origins with no known causes (Adam et al., 2020 in press). Several other malformations and disruptions occurring later in development have been attributed to twin-twin transfusion syndrome (TTTS), and intrauterine fetal demise of a co-twin (IUFD), sometimes 
called vanishing twin. Placental disorders associated with these later complications include unequal placental sharing, placental anastomoses (vessels from one twin being drained by the cotwin forming a unidirectional shunt), and placental inflammation. Additional risk factors include use of assisted reproductive technology (ART), young or old maternal age, prematurity, and low birth weight [Hall, 2003; Painter et al., 2013].

Large gaps in our understanding of twinning-associated neurodevelopmental disorders remain, particularly for later defects in brain morphogenesis. Neurodevelopmental outcomes have been reported in many large twin series, but most provide scant data on the underlying morphological abnormalities, describing non-specific features such as microcephaly or ventriculomegaly, or late gestation injuries such as cerebral infarcts, multicystic leukoencephalopathy, periventricular leukomalacia or intraventricular hemorrhage [Ortibus et al., 2009; Scheller and Nelson, 1992; Zhang et al., 2013]. Brain malformations have rarely been mentioned. We found reports of 48 infants with well documented malformations or disruptions over the past 50 years, consisting of single reports or small series with widely varying details. When provided, neuropathology or imaging figures have been limited, rarely demonstrating the full scope of the malformation or disruption. Further, most reports have focused exclusively on $M Z$ twins, leaving much less known about DZ twins. Thus, the nature, causes and spectrum of twinning-associated brain malformations and disruptions remain poorly understood.

Here, we analyze the brain imaging phenotypes along with data on zygosity, sex and IUFD in 56 proband twins with abnormal brain imaging including 13 previously reported with limited data, 
add brain imaging data for 7 additional less severely affected co-twins, and compare our data to brain imaging or neuropathological data on 48 previously reported twins. In comparison to the literature series, we observed far more diverse patterns of brain malformation and disruption and the occurrence of a similarly wide spectrum of brain abnormalities in both MZ and DZ twins. We also found a small, non-significant trend toward affected males, and many examples of brain malformations and disruptions in pregnancies complicated by TTTS or in utero death of a cotwin. These same patterns of malformation and disruption are seen in single births, leading us to hypothesize that similar mechanisms likely contribute to these malformations and disruptions in singletons as well as twins.

This article is protected by copyright. All rights reserved. 


\section{METHODS}

The human subject database of severe neurodevelopmental disorders maintained by the senior author contains data from more than 10,000 individuals with brain malformations or disruptions diagnosed on brain imaging studies. The database has a very strong bias toward abnormalities seen on brain imaging, especially malformations, but no recognized bias for sex or zygosity. We searched the database for twins and other multiple births and found records of 135 twins from

106 twin pairs (including 1 surviving triplet included as a twin), in which one or both co-twins had a neurodevelopmental disorder with abnormal brain imaging: 77 with one twin affected and 29 with both affected. When both twins were affected (concordant for affected status, but usually discordant for severity), the more severely affected cotwin was designated as the proband twin, or the firstborn when both were similarly affected. All healthy and developmentally normal cotwins were excluded.

\section{Inclusion and exclusion criteria}

We found 135 twins in our initial sweep and hand curated data to exclude those with insufficient data and those with known or likely genetic disorders as our intent was to study disorders linked to the twinning process (Appendix 1). We excluded 36 twins (27 proband twins and 9 affected cotwins) because of insufficient data, 19 (12 proband twins and 7 cotwins) because of positive results from any genetic testing, and 16 (10 probands and 6 cotwins) based on clinical diagnosis of a genetic disorder. One twin was excluded with a positive test for cytomegalovirus. Most twins had no cytomegalovirus or genetic testing performed, so that lack of testing was not used as an exclusion criterion. We included three probands (two unrelated twins and one triplet: 
LR03-055, LR06-117 and LR12-410) who were born as extremely low gestational age newborns (ELGAN: 22-26 weeks-gestation, wkg), which is another rare cause of CBLH [Hintz et al., 2015].

This left 56 proband twins and 7 less severely affected cotwins for this study. When analyzing the spectrum of brain malformations and disruptions we included probands and their affected cotwins. However, when analyzing zygosity and sex ratio, we analyzed data on proband twins only to avoid counting dependent events (twin births) twice, and excluded twins with known zygosity. This left 41 proband twins with known zygosity. We included one proband twin with duplication 22q11.2 (LR12-410) and another with duplication 15q13.3 containing the CHRNA7 gene (LR12-313a2) because their brain malformations could not be explained by these common duplications. We excluded the cotwin (LR12-313a1) with the 15q13.3 duplication, as his clinical diagnosis of autism is typical of this duplication.

\section{Ethical considerations and data sharing}

This study was completed under a human subject research protocol that was approved by the Institutional Review Board at Seattle Children's Hospital. Parents for the two children shown in the figures gave their permission with signed consent to publish their photographs. The data that supports the findings of this study are available in the Tables and Appendices of this article. Some additional individual level data is available on request.

\section{Review of phenotype data}

This article is protected by copyright. All rights reserved. 
We reviewed detailed clinical information for all 56 twin pairs, focusing first on zygosity, sex and cotwin sex, and then on use of any assisted reproduction technology (ART), history of IUFD, gestational age at birth defined as the time elapsed between the first day of the last normal menstrual period and the day of delivery [Engle et al., 2004], maternal age, and other prenatal complications. The basis for assigning DZ, MZ or unknown zygosity (UZ) status is shown in Appendix 2. Next, two of the authors (TC, WBD) reviewed brain imaging studies independently, looking for any brain malformations or disruptions, as defined by an International Working Group on errors of morphogenesis [Spranger et al., 1982]. We also recorded details regarding the precise location, symmetry, and severity gradient of each malformation or disruption.

\section{Separation into subgroups by brain imaging}

To create a rational framework for analysis, we separated our cohort into three subgroups based on fundamental embryologic principles, neuroimaging findings, and neuropathology when available. The three groups include (1) malformations of cortical development (MCD, Table 1); (2) cerebellar malformations (Table 2), and (3) prenatal brain disruptions (BRD, Table 3). Three different types of MCD were seen in this series including polymicrogyria (MCD), several types of subcortical malformation (SUB), and periventricular nodular heterotopia (PNH)[Guerrini and Dobyns, 2014; Leventer et al., 2010; Oegema et al., 2019; Parrini et al., 2006]. The cerebellar malformations included Dandy-Walker malformation (DWM), diffuse and vermis-predominant cerebellar hypoplasia (CBLH), mega-cisterna magna with $\mathrm{CBLH}$, and Blake's pouch cyst. All but DWM were combined into a single CBLH group. The BRD included hydranencephaly, porencephaly, multicystic encephalopathy, and less specific white matter volume loss. For twins 
with evidence of abnormalities fitting more than one of these groups, we analyzed zygosity and sex as part of the group with earlier presumed gestational origin, usually the MCD group.

\section{Literature review}

We performed a detailed review of the literature by PubMed searches using the search term "twin" plus one of the following: "discordant", "Dandy-Walker", "fetal demise", "heterotopia", "polymicrogyria", or "schizencephaly". From this we found reports of 48 individuals with brain malformations or disruptions from 22 publications over 47 years (Appendices 3-6).

\section{Population based data}

We compared zygosity and sex data from our cohort with a large population-based data set of 1493 twin pairs born in British Columbia between 2000 and 2010 [Jahanfar and Lim, 2018], as these data were all linked to placental pathology reports that provided a high level of accuracy regarding the chorion and amnion. We estimated zygosity using Weinberg's Differential Rule [Fellman and Eriksson, 2006]. While data on larger cohorts of twins are available, the data on placentation and placental pathology are less well curated in these reports. We used the same data set to analyze the sex ratio.

\section{Statistical Analyses}

Statistical analyses were performed using the two-tailed Chi-square test, or Fisher's exact test for any $2 \times 2$ pairwise comparisons.

This article is protected by copyright. All rights reserved. 


\section{RESULTS}

We analyzed clinical and brain-imaging data on 56 proband twins and 7 less severely affected co-twins ascertained over 30 years by the senior author and divided them into 3 groups based on the type of malformation or disruption and presumed gestational timing (Figure $1 \mathrm{~A})$. These included 34 (61\%) proband twins with MCD including 5 with co-occurring CBLH-DWM, 12 (21\%) with CBLH-DWM and normal gyral pattern, and 10 (18\%) with brain disruption and associated volume loss (Table 4). All three groups demonstrated a wide range of brain phenotypes. The less severely affected co-twins were classified in the same group (MCD) for 5 twin pairs, and in different groups (MCD-BRD and BRD-CBLH) for the remaining 2 twin pairs. The proband group included more males than females (31M, 25F) and almost equal numbers of $\mathrm{DZ}$ and $\mathrm{MZ}$ twin pairs (19DZ, 22MZ, 15UZ). Data from the literature cohort $(\mathrm{N}=48)$ documented most of the same malformations and disruptions but with less detail regarding distribution and associated abnormalities.

\section{Spectrum of Malformations and Disruptions}

Most published reports emphasize schizencephaly and DWM as the typical malformations, and porencephaly as the most common disruption observed in twins. However, our experience over many years has shown a wide spectrum of brain malformations and disruptions in twins. We will examine these by first providing detailed reports of one stillborn MZ twin pair and three other discordant twins with instructive clinical histories. The first (LP93-085a1/a2) involves IUFD of both $\mathrm{MZ}$ cotwins in the late $2^{\text {nd }}$ trimester and provides one of the most accurate estimates of gestational timing available for polymicrogyria (PMG). The second is a discordant DZ twin girl 
(LP97-138) with detailed neuropathological examination that documents the MCD. The third is a discordant MZ twin boy (LR12-313a2) with high-resolution brain imaging that shows many of the twinning-associated brain malformations seen across the entire cohort as well as amyoplasia, while the fourth is a discordant MZ twin girl (LR18-005) with an MCD, congenital contractures, and intestinal atresia.

\section{Clinical Reports}

LP93-085a1/a2. The female proband twin "B" (or a2) and her same sex cotwin "A" (or a1) were both delivered stillborn at 24 wkg. Their 31-year-old mother (G2P1) had no significant health problems and had routine prenatal care. A prenatal US at $15 \mathrm{wkg}$ showed viable twins, with membranes interpreted as monochorionic-diamniotic, consistent with $\mathrm{MZ}$ twins. A subsequent US at 22 wkg showed IUFD as well as polyhydramnios and cardiomegaly of twin A that were attributed to TTTS as the recipient twin. The proband and donor twin remained viable with no obvious malformations. A third prenatal US at 23 wkg showed that twin B was living but now had ventriculomegaly and other abnormalities interpreted as cortical atrophy or hydrocephalus. By the next week, twin B had also died. Vaginal delivery was induced at $24 \mathrm{wkg}$.

At autopsy, twin A was small (average for $21 \mathrm{wkg}$ ) and had cardiomegaly but no malformations. The brain (54 g unfixed) was severely macerated and could not be examined. The proband twin B (LP93-085a2) was slightly small for dates (average for $23 \mathrm{wkg}$ ). The brain (52 $\mathrm{g}$ unfixed) exhibited atrophy and an irregular cortical surface suggestive of PMG in the frontal and parietal regions corresponding to the distribution of the internal carotid artery (Figure 2A-E). The 
changes were attributed to effects of acute and chronic hypovolemia and ischemia. Histology showed PMG in evolution (Figure 2F). The placenta was fragmented and showed evidence of acute chorioamnionitis so that chorionicity could not be confirmed by pathologic examination.

LP97-138. This girl was born at term following a pregnancy complicated by IUFD of her male co-twin at 16-19 wkg based on serial ultrasound studies. Her birth weight and birth length were normal (50-67th percentiles), but her OFC was only $29 \mathrm{~cm}$ (-4 standard deviations, SD). She had global developmental delay, poor head control and feeding, spasticity and athetoid movements, as well as onset of seizures at 4 months. Gastrostomy feeding was required. Low resolution brain MRI (Figure $3 A-C$ ) at 5 months showed an extensive MCD most consistent with PMG, numerous areas of abnormal signal similar to gray matter beneath the cortex, and patchy but extensive signal changes in white matter suggesting injury.

By 6 years, she had precocious puberty, episodes of unexplained hypothermia, and signs of pituitary insufficiency, consistent with pituitary-hypothalamic dysfunction. Intercurrent illnesses often triggered adrenal crises. Her later years were complicated by profound intellectual disability, spastic quadriparesis, seizures, panhypopituitarism, temperature instability, osteoporosis, obstructive sleep apnea, hypertension attributed to steroid treatment for adrenal insufficiency, severe adrenal crises when ill, and asthma. She died during an intercurrent illness at 19 years.

On gross examination, the brain was abnormally small (fresh weight 570 grams) with relatively 
symmetrical bands of "cobblestone-like" polymicrogyric cortex running along the dorsal surfaces of the frontal, parietal and occipital lobes, appearing most severe in the posterior perisylvian regions (Figure 3D-F). A mid-sagittal section demonstrated a corpus callosum abnormality consisting of a markedly thinned segment of posterior body bounded by thickened anterior body/genu and splenium. Of note, the region of thin corpus callosum mirrored the level of the most severely affected cortex. Coronal sections revealed firm, gliotic white matter with multifocal subcortical heterotopia and $\mathrm{PNH}$ in addition to cystic lesions at the gray-white interface of the posterior parieto-occipital cortices (Figure 3G-J). Both hippocampi were malformed with a hyper-rotated appearance. The brainstem showed focal atrophy and gliosis of the cerebral peduncles with small and atrophic medullary pyramids.

Histologic examination revealed markedly abnormal cortex characterized by hyperconvoluted, fused, and often piled-up gyri with variable cytoarchitecture (Figure 3J). Some regions lacked laminar organization and showed marked thickening intermediate between an unlayered type of PMG and pachygyria, while other regions demonstrated more typical four-layered PMG. A variably dense gliovascular scar covered the surface of much of the abnormal cortex. Microscopic examination confirmed the presence of grossly apparent subcortical heterotopia and PNH (Figure 3K). The cysts at the gray-white matter junction of the parieto-occipital cortex were found to correspond to cystically dilated perivascular spaces containing rare hemosiderin pigment. Baseline gliosis was seen in the majority of the sampled subcortical tissues with reactive gliosis and scattered microcalcifications in the periventricular white matter and hypothalamus. 
LR12-313a2. This boy and his MZ twin brother were born at 36 wkg via cesarean section after an uncomplicated pregnancy. Prenatal US had revealed DWM at 17 weeks that was confirmed

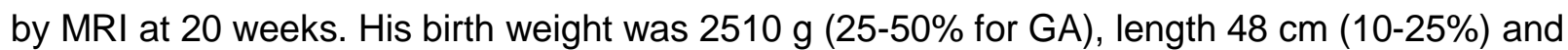
OFC $34.5 \mathrm{~cm}$ (10-25\%). On exam, he had congenital extension contractures of both elbows and flexion contractures of the wrist and hands, more severe on the left (Figure 4A-C), as well as mild contractures of his right foot consistent with three-limb amyoplasia [Hall et al., 2014]. His early development was delayed. At 6 months, his OFC began to increase rapidly. A brain MRI at 10 months showed hydrocephalus, treated with a ventriculoperitoneal shunt. At 7 years, he was nonverbal and unable to walk. He fed well on a soft diet but was unable to chew. No seizures had been observed.

Brain MRI (Figure 4D-L) demonstrated mildly asymmetric dysgyria with subtle irregularity of the gray-white junction consistent with PMG involving the parietal and occipital lobes, more severe right than left and over mesial compared to lateral surfaces. Beneath these regions were large $\mathrm{PNH}$ that encased the trigones and occipital horns, and on the right extended frontally along the body of the right lateral ventricle. The PNH on both sides were connected to the overlying dysgyria by several small columnar subcortical heterotopia (Figure 4G-H). The corpus callosum was short with a small splenium. The brainstem appeared normal. The cerebellum was small and dysplastic with a very small and upwardly rotated vermis and unpaired caudal lobule (a.k.a. Dandy-Walker tail, Figure 4E), mildly small right hemisphere, and moderately small left hemisphere with a large slice of the left middle cerebellar peduncle and adjacent cortex missing, 
representing an atypical cerebellar cleft (Figure 4F and L). The posterior fossa was markedly enlarged with an elevated torcula.

His twin brother had mild developmental delay and developed behavioral features consistent with autism by 3 years. Both twins carry a small, maternally inherited $\sim 680 \mathrm{~kb}$ duplication in 15q13.3 that contains CHRNA7, a well-known copy number variant which has been associated with autism, but not brain malformations.

LR18-005. This girl was born as twin B following a monochorionic-diamniotic twin pregnancy Prenatal ultrasound detected echogenic bowel and probable high intestinal atresia at $15 \mathrm{wkg}$, prompting evaluations that led to diagnosis of severe TTTS (she was the donor twin). Laser ablation of the vascular anastomoses was performed at $17 \mathrm{wkg}$. Prenatal ultrasounds also detected severe intrauterine growth retardation (IUGR) and clubfeet, but no brain abnormalities. Twin A had normal ultrasounds.

This girl and her cotwin were born by elective cesarean section at 32-0/7 wkg with Apgar scores 7-8-9 at 1, 5 and 10 minutes. Her birth weight was $650 \mathrm{~g}$ (-2.8 standard deviations, SD), length $25.0 \mathrm{~cm}(-6.1 \mathrm{SD})$, and OFC $31.0 \mathrm{~cm}$ (93\%). Her neonatal exam demonstrated mild dysmorphic features consisting of a large anterior fontanelle, tall forehead, downslanting palpebral fissures, short neck, fixed lower extremity contractures involving both hips and knees with deep dimples over both hips, flexion contractures of both ankles (Figure 5A-B), and mild contractures of her right hand. No birthmarks were seen including no facial capillary malformations. Jejunal atresia 
was confirmed and a jejunostomy was placed on day 1 of life (Figure 5C-D). Multiple x-rays including a skeletal survey within the first week of life showed diffusely demineralized bones, shallow acetabular roofs, and multiple fractures including compression fractures of $L 4$, healing fractures of the distal femur, a buckle fracture of the distal left radius, and a transverse fracture of the distal right radius. Most of the fractures were in a healing phase, indicating that many or all occurred prenatally. Medical complications in the NICU included respiratory distress syndrome, transient hypoglycemia, thrombocytopenia, a patent ductus arteriosus that closed spontaneously, fenestrated atrial septal defect with intermittent premature atrial contractions, possible duplication of the right kidney, and possible adrenal insufficiency. At 3 months, her jejunum was re-connected. She has needed multiple surgical procedures for these and other problems including Achilles tenotomies for clubfeet; inguinal hernia repair, strabismus surgery (all bilateral), feeding tube placement, and repair of a tethered spinal cord.

By 1-9/12 years, she had made significant developmental progress and was using a few words. Her weight was $9.05 \mathrm{~kg}$ (4th percentile or -1.74 standard deviations, SD), height $72 \mathrm{~cm} \mathrm{(-4.14}$ SD), and OFC $44.2 \mathrm{~cm}$ (-1.98 SD). She had a normal facial appearance, but her legs appeared mildly short for age. Her arms and hands were normally formed. She had mild contractures at the hips and knees and dimples over both hips, which had improved since birth. She had residual clubfeet, with very limited plantar flexion (Figure 5E-G).

Brain MRI at 4 months (Figure $4 \mathrm{H}-\mathrm{K}$ ) showed bilateral but mildly asymmetric (worse on the right and posteriorly) dysgyria consistent with PMG in the posterior frontal, temporal, and parietal 
regions that spared the occipital lobes. The white matter had moderately reduced volume beneath the areas of abnormal cortex, and the lateral ventricles were mildly enlarged (again worse on the right), and the corpus callosum was mildly thin. The brainstem and cerebellum were normal.

Her twin sister was born with birth weight $1.9 \mathrm{~kg}$ but did well and at age 2 years is in good health with normal development. Genetic analysis using a panel of polymorphic markers confirmed that they were $\mathrm{MZ}$ twins.

\section{Malformations of cortical development (MCD)}

This series. The most common malformation in this group was PMG, found in 37 of 39 twins (here including proband twins and affected cotwins), variably associated with pia-ependymal clefts, absent septum pellucidum, subcortical malformations (SUB) consisting of either deep infolding or heterotopia, PNH or both SUB and PNH, obvious hemispheric asymmetry (Table 1), and sometimes cerebellar malformations (Table 2). Schizencephaly or "cleft brain" consists of unilateral or bilateral pia-ependymal clefts with PMG lining the cleft and variable extent of the surrounding hemisphere(s) and has been classified as a separate MCD. However, our data suggest that it represents the severe end of a continuous series of MCD, so we will hereafter describe it as "PMG with cleft". Examples of the diverse patterns of MCD are shown in multiple figures to capture the diversity of presentations (Figures 2-9). 
PMG with cleft was observed in 8/37 (22\%) twins. Absent septum pellucidum (ASP) was noted in only 5 twins with PMG but occurred significantly more often in individuals with (3 of 8 [38\%]) than without clefts (2 of 31 [7\%], P=0.0491 using Fisher's Exact Test). One twin had severe hypopituitarism (LP97-138 described above).

SUB were found in 12/39 (31\%) and PNH in 15/39 (38\%) twins with distribution equally divided between anterior- and posterior-predominant. The largest subgroup comprised 8 individuals with fan-like or columnar SUB extending from underlying PNH to the overlying PMG (Figures 3, 4, 7). Only 2/39 (5\%) twins had PNH without PMG (LR20-090, LR20-091) and only one (LR15-063) had small scattered SUB in the anterior frontal lobes with PMG but not PNH (Figure 7). The rates of SUB or PNH were similar in the cleft and no cleft groups. Finally, 23/39 (59\%) twins had asymmetric malformations that were equally divided between the right and left sides.

Another 5/39 (13\%) twins including one concordant MZ twin pair (LR01-283a1/a2) and 3 discordant MZ twins (LP98-090, LR12-429, LR20-092) have a rare MCD that we originally described as bilateral parasagittal parietooccipital PMG [Guerrini et al., 1997; Leventer et al., 2010], but now designate PMG with "deeply infolded heterotopia-parieto-occipital subtype" [Oegema et al., 2019].This malformation consists of PMG that extends from the posterior perisylvian to mesial occipital region with deep infolding of the dysplastic gyri that often (but not always) compresses the trigones and occipital horns (Figure 9).

This article is protected by copyright. All rights reserved. 
Literature series. In this group, all 14 discordant twins had PMG, but only 1/14 (7\%) had a piaependymal cleft (Appendix 3). None had absent septum pellucidum. SUB and PNH were each reported in 9/14 (64\%) twins including 8 with columnar or fan-like SUB heterotopia extending from underlying $\mathrm{PNH}$ to the overlying cortex as shown in published figures (several examples are listed in Appendix 6). Among subjects with cortical malformations, 4/14 (29\%) had highly asymmetric MCD. Within these subjects, two were more severe on the right and two more severe on the left.

\section{Cerebellar hypoplasia (CBLH) and Dandy-Walker malformation (DWM)}

This series. The 19 individuals in this group (12 proband twins plus another 6 from the MCD group and one affected cotwin) had cerebellar malformations that varied from classic DWM to diffuse or vermis predominant CBLH, variably associated with brainstem hypoplasia, cerebellar clefts, or obvious cerebellar asymmetry (Table 2 and Figure 10). One twin with diffuse CBLH had severe brainstem hypoplasia and a cyst in the right ambient cistern compressing the midbrain, while another had a cerebellar cleft. Obvious cerebellar asymmetry was observed in 8/19 (42\%) twins, equally divided between CBLH and DWM and between right and left side predominance. DWM was more common in $\mathrm{MZ}$ twins (4/6 MZ [67\%]) while CBLH was more common in DZ twins (1/8 MZ [13\%]), but the difference was not significant.

Literature series. The data available for this group were limited. All but one of the 16 twins in this group were reported to have DWM rather than CBLH (Appendix 4), although the diagnosis in 10 fetuses was based on prenatal ultrasound without confirmation by MRI. These 10 fetuses 
comprised 10/660 (1.4\%) monochorionic (i.e. MZ) twin pregnancies referred to a single large maternofetal center, and included 1 liveborn child who was lost to follow-up, 3 intrauterine deaths of the proband with DWM, and 5 terminations [Kontopoulos et al., 2008].

\section{Brain disruption (BRD)}

This series. The remaining twins had prenatal clastic encephalopathies that have historically been separated by severity into hydranencephaly (HYDN, cerebral hemispheres replaced by a thin-walled, fluid-filled cyst), porencephaly (POR, any fluid-filled cavity in the fetal or neonatal brain), multicystic encephalopathy (multiple cysts, overlaps with POR) or white matter volume loss without cysts. Our series included 2/10 (20\%) with HYDN, 3/10 (30\%) with POR, and 5/10 (50\%) with white matter volume loss without cysts (Table 3 and Figure 11). Only one child had significant asymmetry. As expected, ventriculomegaly was more common with HYDN or POR than with less specific white matter volume loss.

Literature series. The data available for the 18 twins in this group were also limited. The most severe were described as HYDN, and others as POR, multicystic encephalopathy, atrophy or other terms such as HYDN-POR (Appendix 5). The descriptions and figures did not provide enough detail to allow any patterns to emerge. The data suggest a trend toward more males than females, and a predominance of $M Z$ twins, but most reports included only MZ twins, so the rates of $\mathrm{MZ}$ and $\mathrm{DZ}$ twins cannot be reliably compared.

\section{Disruptions outside of the brain}

This article is protected by copyright. All rights reserved. 
Congenital anomalies of other brain regions or the spinal cord, or outside of the brain were seen in 10 of $56(18 \%)$ twin probands from our series and reported in several from the literature. The anomalies have included pituitary insufficiency, spinal cord atrophy, amyoplasia, less specific patterns of congenital contractures, amniotic band disruption sequence, gastroschisis, jejunal atresia, and cutis aplasia of the scalp (Table 4 and Figures 3-4). Two unrelated twins had PMG and bilateral vocal cord paralysis, which has not previously been described in twins. However, congenital vocal cord paralysis has been reported with PMG [Steiner et al., 2013], and we have reviewed independent data on five unrelated singletons with PMG and vocal cord paralysis, which suggests an association.

\section{Sex and Zygosity}

We examined sex and zygosity of our twin probands and compared them to the literature twin cohort as well as to expected ratios from population data (Figure 1B and Table 5). We were able to determine zygosity for only 41 of 56 twin pairs (Appendix 2), mostly due to limited data on placentation and zygosity in twin pairs with IUFD and limited access to perinatal records for children ascertained during the early years of this study. Our cohort included an excess of MZ twin pairs (22/41 MZ [54\%]) that was significantly higher than in the population cohort (482/1448 $M Z$ [33.3\%], $P=0.0119$; Table 6). However, the even split between $D Z$ and $M Z$ twin pairs in our cohort differed dramatically from the large excess of MZ twins in the literature cohort of twins with severe brain malformations and disruptions (45/46 MZ [98\%], P<0.0001, Table 6).

The three-way comparison was also highly significant $\left(\chi^{2}=86.7029, \mathrm{P}<0.0001\right.$; Table 6$)$. The observed zygosity ratio (19 DZ, $22 \mathrm{MZ}$ from Appendix 2) included fewer DZ twins that the 
predicted ratio (DZ 26, MZ 19) using Weinberg's Differential Rule [Fellman and Eriksson, 2006]. We next asked whether the 15/56 (27\%) UZ twin probands were a confounding factor with three additional analyses. In the first, we changed the 4 same sex twin pairs for whom zygosity was based on parental report from MZ or DZ to UZ, and in the second changed all UZ twins to MZ. For both, all pairwise and 3-way comparisons remained highly significant (Appendix 7). In the last, we changed all UZ twins to DZ (an unlikely scenario), which changed the difference between the population cohort and our cohort to not significant.

Small deviations in the sex ratio and twin pair sex ratio toward males were seen in both our series (31/55 male [56\%]) and the literature cohort (24/41 [59\%]; Table 5). However, these did not differ significantly from the population-based twin cohort.

\section{Intrauterine fetal demise, prematurity and ART}

Our series included 13 twin pairs with IUFD of a cotwin, and we found reports of another 25 in the literature reporting wide and overlapping variation in timing of the brain malformation or disruption, with IUFD associated with MCD from 6-26 wkg, CBLH-DWM from 9-28 wkg, and BRD from 10-37 wkg with a mean of $31 \mathrm{wkg}$ (Table 7). We also assessed gestational age at birth for all subjects, when known. Our series included three ELGAN twins (one a triplet), and eight less premature twins born at 28-32 wkg. The remainder were born at or close to term. ART primarily in vitro fertilization was used for 7 pregnancies across all three groups, a number too small for useful analysis.

This article is protected by copyright. All rights reserved. 


\section{DISCUSSION}

"When one twin has a malformation, the cotwin may also have a malformation, although not necessarily the same as the first twin" [Myrianthopoulos, 1976]. With this one sentence, Dr. Ntinos Myrianthopoulos, then Chief of the Birth Defects and Genetic Disorders section at the National Institutes of Health, foretold knowledge that would emerge over the next 40 years.

We now know that twinning is a major risk factor for adverse neurodevelopmental outcome and that twins are over-represented in large cerebral palsy cohorts [Livinec et al., 2005; Scheller and Nelson, 1992]. The causes are heterogeneous and involve both maternal and fetal factors, as well as complications related to prematurity. Teasing out the different underlying mechanisms has been difficult, but it is clear that twinning is a risk factor for abnormal brain development in utero in addition to late perinatal neurological complications. While many studies have described poor developmental outcomes in twins, hypoxia and ischemia in late pregnancy are described as the main cause, with little data on malformations or severe brain disruptions.

Only a few reports describe large series of (usually discordant) twins with congenital anomalies, and these provide scant individual level data [Glinianaia et al., 2008; Mastroiacovo et al., 1999; Myrianthopoulos, 1976; Schinzel et al., 1979] and no data at all on sex of twins or twin pairs. We were able to collate data from 48 twins with brain malformations or disruptions from 22 reports over more than 50 years, but the data were often incomplete, especially the imaging findings. Thus, significant gaps in knowledge remain. For example, which of the many structural defects observed in twins occur together and which do not? Among twins with poor neurodevelopmental 
outcomes, what are the most likely causes and how can these be recognized? And are the risks largely restricted to MZ twins, especially for malformations, as many studies suggest?

Here we describe and analyze individual level data on 56 twins with brain malformations and disruptions along with 7 less severely affected cotwins referred to the senior author over 30 years (1990-2020), with a strong referral bias for structural defects especially malformations, but not for sex or zygosity. This cohort more than doubles the number of twins reported with brain malformations and severe disruptions. Our individual level data defines a spectrum of MCD, CBLH-DWM and BRD that are much broader than generally recognized, although a detailed review of prior reports (mostly single clinical reports) found some documentation for most of them. Our findings, particularly our data on zygosity, associated anomalies and the trend toward males, contribute to our understanding of the pathogenesis of PMG, brain heterotopia, CBLH and DWM, and BRD that are relevant for singletons as well as twins. We recently demonstrated a molecular diagnosis (solve) rate of $16 \%$ with genetic testing for Dandy-Walker malformation [Aldinger et al., 2019], and expect to find a similar modest solve rate for PMG and heterotopia based on our unpublished experience and diverse published data that we review in the section on pathogenesis below.

\section{The spectrum of structural defects of the brain in twins}

We identified three main groups of structural brain defects in twins involving both the cerebral hemispheres and cerebellum, as well as presumably later originating disruptions. Of course, these abnormalities can and do co-occur.

This article is protected by copyright. All rights reserved. 
MCD. Our data define a broad spectrum of MCD that encompasses PMG, deeply infolded PMG that presents as a subcortical malformation, gray matter lined pia-ependymal clefts, subcortical columnar and fan-like heterotopia, and PNH in many combinations (Table 1, Appendices 3 and 6, Figures 2-9). The PMG is usually bilateral but often asymmetric and can be unilateral. It can be extensive or localized to almost any region of the brain although posterior localization seems to be more common. We now view schizencephaly (cleft brain) as part of a broad spectrum of MCD associated with defects in vascular perfusion in twins as well as in singletons (vide infra) rather than a malformation in its own right, leading us to change the descriptive term for this malformation to "PMG with cleft". Some twins with PMG especially those with clefts also had absent septum pellucidum [Hayashi et al., 2002]. Several prior reports delineated a "septo-optic dysplasia (SOD)-schizencephaly" syndrome or "SOD plus" [Kuban et al., 1989; Miller et al., 2000], which we now view as simply another point along a broad spectrum of MCD associated with vascular perfusion defects. Among these MCD, only PMG with clefts has been recognized as having increased frequency in twins [Curry et al., 2005], although individual reports have described PMG with cleft on one side of the brain and PMG without cleft on the other [Leventer et al., 2010]. Thus, we found a spectrum of MCD within "PMG with clefts" that includes PMG with open-lip clefts at the severe end, and deep clefts lined by PMG that do not communicate with the lateral ventricles at the less severe end.

SUB and PNH have not been widely recognized as twinning-associated anomalies. However, most of the MCD patterns that we describe in twins including SUB and PNH have (rarely) been 
shown in published figures. We found descriptions and/or figures showing $\mathrm{PNH}$ with overlying subcortical fan-like or columnar subcortical heterotopia and PMG in 8 unrelated twins, and posterior predominant PNH in another (Appendix 6 and Appendix additional references). We show another well-documented example in subject LP97-138 (Figure 3).

The cause of PMG with deeply infolded heterotopia-parieto-occipital subtype, previously designated bilateral parasagittal parietooccipital PMG, has been unknown, and the authors suspected that it was genetic [Guerrini et al., 1997; Oegema et al., 2019]. However, our report of this rare malformation in $5 \mathrm{MZ}$ twins including one concordant $\mathrm{MZ}$ twin pair and 3 discordant $M Z$ twins (with IUFD of the cotwin for two of the three) supports a non-genetic cause, such as a prenatal vascular perfusion defect.

CBLH-DWM. Next, our data demonstrate a wide spectrum of cerebellar malformations that encompass diffuse or partial CBLH frequently associated with unilateral or highly asymmetric cerebellar hemisphere hypoplasia, and cerebellar clefts, as well as classic DWM (Table 2). While most of these twins had isolated cerebellar malformations, 6 of 19 (32\%) individuals also had MCD (Tables 1-2 and Figure 4). Unilateral or highly asymmetric cerebellar hemisphere hypoplasia has been attributed to prenatal "vascular" causes including ischemia and posterior fossa-cerebellar hemorrhage, while cerebellar clefts have been attributed to prenatal posterior fossa-cerebellar hemorrhage [Benbir et al., 2011; Massoud et al., 2014; Poretti et al., 2009; Poretti et al., 2008; Poretti et al., 2010]. Neither has previously been associated with twinning. 
DWM has been reported in both concordant and discordant twins in several single reports over the past 65 years including a discordant twin described by Benda in 1954 using imaging tools available at the times of these reports [Benda, 1954; Haller et al., 1971; Jenkyn et al., 1981; Koul et al., 2000; Lennon, 2002; Li and Liao, 2009; Shen, 1989]. Further, analysis of 169 individuals with DWM and 10,200 controls from the National Birth Defects Prevention Study (NBDPS) found an increased association of DWM with twinning [Reeder et al., 2015]. Our data supports these reports and provides better imaging that documents classic DWM with an unpaired caudal lobule of the vermis or Dandy-Walker "tail" [Aldinger et al., 2019; Bernardo et al., 2015]. Whole exome sequencing in 12 twins with CBLH or DWM in our series was negative [Aldinger et al., 2019]. Also, DWM as defined by prenatal ultrasound was found in 10 of 660 (1.5\%) monochorionic (therefore also MZ) twin pregnancies, always involving only one of any twin pair [Kontopoulos et al., 2008]. The affected twin was the smaller twin in 8 of 10 pregnancies, and TTTS was documented in 4 of 10. This study concludes that DWM (as defined by prenatal ultrasound imaging) is more likely to occur in the smaller twin of a twin pair and more likely to be associated with growth restriction. These findings may assist in our understanding of the pathogenesis of cerebellar malformations [Kontopoulos et al., 2008].

We found classic DWM in more MZ twins and other forms of CBLH in more DZ twins, but the difference was not significant due to small numbers. If validated with larger numbers, this difference would suggest important differences in pathogenesis.

This article is protected by copyright. All rights reserved. 
Brain Disruptions. Finally, our data demonstrate wide variation in severity of brain disruptions without evidence of a (developmental) malformation in the strict sense (Table 3). Several other twins in our MCD group also had evidence of brain disruption, especially the two examined at autopsy (Figures 1-2). Brain disruptions are abnormalities of the brain thought due to destruction of previously formed normal brain tissue. A hallmark feature of brain disruption is loss of brain tissue, either gray matter, white matter or both. This definition separates them from primary malformations, in which the brain never formed normally from the outset. While HYDN and POR have been described in twins, we found less specific cerebral volume loss especially involving white matter in 5 of 10 subjects in this group.

\section{Zygosity, sex ratio and the placenta}

Zygosity. Many studies have shown higher rates of malformations, disruptions and abnormal neurodevelopmental outcomes in $\mathrm{MZ}$ (or monochorionic) compared to $\mathrm{DZ}$ (or dichorionic) twins, prompting us to examine zygosity in our cohort [Glinianaia et al., 2008; Hall, 1996; Hall, 2003; Kosinska-Kaczynska et al., 2016; Scheller and Nelson, 1992; Tosello et al., 2020]. We looked for and found a significant excess of $M Z$ twins compared to a population cohort (Tables 5-6), although the difference was not significant if we used the predicted zygosity ratio from Weinberg's Differential Rule or re-classified all UZ twins as DZ. We also found a significantly higher proportion of DZ twins (and thus lower proportion of $M Z$ twins) compared to a literature cohort of twins with brain malformations or disruptions. Further, the proportion of $M Z$ twins remains significantly lower than the literature cohort with any re-classification of our observed zygosity ratio (i.e. using the predicted ratio or reclassifying all UZ twins as either $\mathrm{DZ}$ or $\mathrm{MZ}$ ). 
Thus, we found only mild skewing of zygosity toward MZ twins with about equal numbers of DZ and $M Z$ twins in our brain malformation-disruption series. This differs significantly from several other twinning associated syndromes that have marked skewing toward MZ twins. We separate these into recurrent constellations of embryonic malformations such as LBWC, MURCS, OAVS, OEIS, POC and VACTERL [Adam et al., 2020], and recurrent constellations of fetal disruption especially amyoplasia and intestinal atresia [Cragan et al., 1994; Hall et al., 2014]. Several other recurrent constellations of fetal disruption such as gastroschisis and septo-optic dysplasia are increased in twins, but no studies of zygosity have been reported. Our data also differ remarkably from the literature cohort of brain malformations and disruptions, which now suggests considerable reporting bias. The striking difference in the zygosity ratio between these disorders suggests different underlying mechanisms, or at least very different timing.

Sex ratio. Our series and the literature cohort (Table 5) both included a slight excess of males that was not statistically significant, although our twin pair sex data was incomplete as sex of the deceased cotwin with IUFD was rarely available. An excess of male twins was also observed with amyoplasia [Hall et al., 2014]. Some studies of neurodevelopmental outcomes in twins include sex as a variable feature but do not report any differences, implying that any differences were not significant [Dostanic et al., 2018; Tosello et al., 2020]. However, we predict that studies including larger numbers of twins with individual level data will support an increased risk in males based on analysis of twin placentas, discussed below [Jahanfar and Lim, 2018]. Further, the higher frequency of vascular abnormalities in male compared to female placentas might 
explain prior observations that PMG is more common in males than females despite few (and rare) X-linked causes of PMG [Jahanfar and Lim, 2018; Leventer et al., 2010].

The placenta. The near equal proportion of $M Z$ and $D Z$ twins with structural defects found in our cohort has not been reported previously but fits well with a recent comprehensive analysis of 1493 twin placentas from British Columbia [Jahanfar and Lim, 2018]. This study found abnormal anastomoses (unidirectional arteriovenous shunts) in 232/1930 (12.0\%) same sex twins (enriched for MZ) compared to 23/966 (2.4\%) unlike sex twins (all DZ), and unequal placental sharing in 119/1930 (6.2\%) same sex twins compared to 19/966 (2.0\%) unlike sex twins, making abnormal placental blood flow $\sim 3-5$ times more common in MZ compared to DZ twins. Assuming similar severity, this suggests that abnormal outcomes might be expected to be 3-5 times more frequent in $M Z$ twins, and indeed one recent study reported that medical terminations (for diagnosis of severe, lethal or incurable diseases) and stillbirths were 3 times more common in MZ than DZ twins [Tosello et al., 2020]. The same British Columbia study of twin placentas found a significantly higher risk of unequal placental sharing and abnormal anastomoses in males compared to females for both same sex twin pairs (enriched for MZ) and opposite sex twins (all DZ), strongly supporting a higher risk for vascular-based complications in males [Jahanfar and Lim, 2018].

Considering data from our series and the British Columbia twin placenta study, we are surprised at the scarcity of reports of twinning-associated brain malformations and disruptions in DZ twins and of higher rates of abnormalities in male twins. We speculate that some prior results might 
be explained by (1) large studies examining group rather than individual level data, (2) use of chorionicity rather than zygosity, and too many studies being restricted to $\mathrm{MZ}$ twins. Future studies should always include both $\mathrm{MZ}$ and $\mathrm{DZ}$ twins, and report twin and twin pair sex.

\section{Gestational timing}

The presumed timing of IUFD has been used to propose gestational ages of susceptibility for the associated brain malformations and disruptions. Adding our data to the literature reports (Table 7), MCD have been associated with IUFD from 6-26 (mean 17-18) wkg, cerebellar malformations from 9-28 (mean 22) wkg, and BRD from 10-37 (mean 24-25) wkg. But this approach is intrinsically flawed as the pathological processes leading to death of a twin are likely to have originated days or weeks before IUFD was confirmed, and decomposition of the deceased fetus may predispose to disseminated intravascular coagulation, thrombosis, emboli and other complications for days to weeks after death of a cotwin. Thus, we view these dates as unreliable for determining the gestational ages of susceptibility for these defects, although they suggest a continuum of sequelae with MCD first, followed by CBLH-DWM and then BRD, with malformations and disruptions sometimes coexisting in individual twins (Table 7).

Correlation with normal brain development (at least for MCD and CBLH) and rare examples of known injuries are likely to be more reliable. For example, we have data on two singletons with PMG whose mothers were involved in severe motor vehicle accidents at 12.5 and 16.5 wkg; the mother of the latter boy had a broken pelvis and was in shock for several hours. We have also reviewed four reports in which fetal posterior fossa bleeds detected at 19-22 wkg were 
associated with DWM or CBLH [Folkerth et al., 2001; Limperopoulos et al., 2010; Sherer et al., 2004; Yuksel and Batukan, 2003].

\section{Pathogenesis of fetal structural defects in twins}

Many prior reports have proposed intrauterine vascular perfusion defects and/or hemorrhage as the primary cause of diverse twinning-associated malformations and disruptions, beginning with the group of brain malformations and disruptions studied in this report (PMG-SUB-PNH, CBLHDWM and brain disruptions especially HYDN and POR) but also including septo-optic dysplasia, amyoplasia, gastroschisis, intestinal atresia, congenital cutis aplasia, and transverse terminal limb defects. The arguments against this mechanism have been most active for gastroschisis, which has been proposed as a primary midline malformation attributed to abnormal folding of the body wall or weakening of the normal attachment of the umbilical cord to the umbilical ring, among others [Feldkamp et al., 2007; Opitz et al., 2019; Rittler et al., 2013]. All the while, the evidence supporting vascular-related mechanisms continues to mount.

From analysis of our data and review of extensive literature, we believe that a preponderance of the evidence strongly supports a vascular hypothesis, noting that this must be viewed broadly to include defective vasculogenesis, diffuse hypoperfusion, thrombosis, emboli and hemorrhage. We recognize that vascular abnormalities may serve as a final common pathway for other proposed mechanisms such as maternal inflammation and high estrogen levels [Jones et al., 2013; Lubinsky, 2012]. Some of the most important data supporting vascular mechanisms are summarized below with a focus on the brain.

This article is protected by copyright. All rights reserved. 
First and foremost is the concept of shared pathogenesis. The malformations and disruptions cited above share several features. The risks of recurrence in families are low or nil. Genetic studies especially whole exome sequencing in a series of affected individuals have not been reported. While several individual genes have been reported, our experience to date suggests that the yield will be moderate at best. Also, most of the phenotypes co-occur in a few affected individuals (Clinical Reports and Table 4). Our series and several reports give examples of twinning-associated MCDs (PMG-SUB-PNH) associated with septo-optic dysplasia, amyoplasia, less specific arthrogryposis, intestinal atresia, cutis aplasia and amniotic band disruption sequence including transverse terminal limb defects [Hall et al., 2014; Mochizuki et al., 2010; Shue et al., 2012; Stevens and Dobyns, 2004; Yamanouchi et al., 2002]. More examples are found in the literature, for example amyoplasia with gastroschisis, intestinal atresia or transverse terminal limb defects [Collins et al., 1986; Hall et al., 2014; Reid et al., 1986; Shenoy et al., 1999], gastroschisis with septo-optic dysplasia or MCDs [Garvin et al., 2016; Jordan and Montezuma, 2015; Kamien et al., 2010; Sullivan et al., 2018] [Curry et al., 2005], septo-optic dysplasia with terminal limb defects [Faivre et al., 2002; Harrison et al., 2004; Pagon and Stephan, 1984], and many others. In our view, the many reports of co-occurrence imply that all or most of these phenotypes have shared pathogenesis, and that any proposed mechanisms must account for this phenomenon. We recently reported a large series of children with SUB that included singletons with defects in vasculogenesis (absent internal carotid artery), aplasia cutis, jejunal atresia, and limb reductions [Oegema et al., 2019].

This article is protected by copyright. All rights reserved. 
Second, the three groups of brain abnormalities in our study are all associated with TTTS and IUGR in twins (i.e. Tables 1-3), usually the donor twin, which implies vascular hypoperfusion [Larroche et al., 1994; Sugama and Kusano, 1994; Tarui et al., 2012; Van Bogaert et al., 1996]. The same is true for the other well studied malformations, especially amyoplasia [Burke et al., 1991; Hall et al., 2014; Patel et al., 2012; Wong et al., 2009]. The vascular and inflammatory abnormalities found in twin placentas, especially abnormal anastomoses and unequal placental sharing, are the proximate cause of TTTS and associated IUGR [Benirschke, 1992; De Paepe and Luks, 2013; Fitzgerald, 2018; Jahanfar and Lim, 2018].

Third, PMG especially with clefts (i.e. schizencephaly) is often localized to specific vascular distributions especially the middle cerebral artery territory, watershed zones, or the periphery of ischemic POR [Dekaban, 1965; Ferrer, 1984; Ferrer and Catala, 1991; Levine et al., 1974;

Richman et al., 1974; Squier and Jansen, 2010]. Also, the common layered form of PMG has a layer of presumed laminar necrosis that resembles other ischemic lesions [Levine et al., 1974; Richman et al., 1974].

Fourth, several of the risk factors identified in epidemiological studies of gastroschisis, which shares pathogenesis with PMG, are vasoactive environmental exposures or medications, for example young maternal age (higher maternal estrogen levels), high maternal estrogen levels from other causes, smoking (which causes vasoconstriction) and vasoactive medications such as aspirin and ibuprofen, decongestants, and drugs of abuse [Torfs et al., 1996; Torfs et al., 1994; Werler et al., 2009; Werler et al., 2002]. Similar exposures have been reported in rare 
children with PMG including a combination of caffeine and ergotamine tartrate at 16-18 wkg [Barkovich et al., 1995], and carbon monoxide exposure [Bankl and Jellinger, 1967; Hallervorden, 1949] at 20-24 wkg.

Fifth, twinning-associated brain malformations, both MCD and CBLH-DWM, have been reported with defects in vasculogenesis and with vascular malformations. In PHACE syndrome, arterial anomalies were found in 70/91 (77\%) affected individuals [Hess et al., 2010]. A later study that included many of the same individuals reported MCD including PMG or heterotopia in 4/55 (7\%) and CBLH or DWM in 15/55 (27\%) individuals [Steiner et al., 2018]. In deletion 22q11.2, PMG has been described in more than 30 individuals making it a rare but recurrent associated malformation [Robin et al., 2006]. Abnormal location or absence (failure to visualize on vascular imaging studies) of the subclavian, carotid or vertebral arteries was described in 38/70 (54\%) individuals with deletion 22q11.2, and at least one individual with PMG (reported as "focal pachygyria") had an absent left internal carotid artery [Johnson et al., 2010; Stransky et al., 2015]. And of course, haploinsufficiency of Tbx1 causes vasculogenesis defects in mouse [Cioffi et al., 2014; Lindsay et al., 2001]. Similarly, an isolated arterial abnormality was described in a 32-week gestation fetus with bilateral central open-lip clefts and lack of blood flow in the right middle cerebral artery that was confirmed after birth [Suchet, 1994]. Going on, PMG and PNH have been seen adjacent to intracranial arteriovenous malformations, whether isolated or in individuals with hereditary hemorrhagic telangiectasia [Chugh et al., 2017; Hung et al., 1996; Klostranec et al., 2019b; Palagallo et al., 2017], and adjacent to less specific vascular malformations [Abe et al., 1997; Klostranec et al., 2019a]. 
Sixth, brain malformations and disruptions have been associated with prenatal hemorrhage in the cerebral hemispheres (causing PMG-SUB-PNH) or cerebellum (causing CBLH-DWM). The best examples include PMG and POR with mutations of COL4A1, COL4A2 or COL18A1, PMG in infants with neonatal alloimmune thrombocytopenia or NAIT [Cavallin et al., 2018; Charsar and Goldberg, 2017; Corbett et al., 2017; Dale and Coleman, 2002; Hildebrandt and Powell, 2002; Keren et al., 2007; Kuijpers et al., 1994; Lopriore et al., 2007; Paisan-Ruiz et al., 2009; Zagaglia et al., 2018], and PMG with severe maternal trauma or prenatal warfarin exposure [Mancini et al., 2001; Pati and Helmbrecht, 1994; Squier and Jansen, 2010]. CBLH and DWM have been observed with prenatal posterior fossa or cerebellar hemorrhage [Limperopoulos et al., 2010; Pichiecchio et al., 2016; Sherer et al., 2004; Shiohama et al., 2017].

These data collectively support a prenatal vascular causation hypothesis and show that nongenetic factors (at least not single gene mutations) during the 2nd and 3rd trimesters cause or predispose to brain malformations and disruptions. However, our analysis does not exclude genetic causes as studies in individuals and families have reported a few causative genes (i.e. CUL4B, MAP1B, NEDD4L, PI4KA), although reports are rare, especially when subtypes of PMG or PNH with severe microcephaly or megalencephaly are excluded. Further, some of the known single gene causes support a prenatal vascular hypothesis, with deletion 22q11.2 including TBX1 (defects in vasculogenesis) and mutations of COL4A1-COL4A2 (prenatal hemorrhage) being good examples.

This article is protected by copyright. All rights reserved. 
We hypothesize that twinning-associated malformations (PMG-SUB-PNH, CBLH-DWM) may be associated with either non genetic or genetic factors that cause or predispose to either fetal hypoperfusion or hemorrhage. The combination of genetic and non-genetic (at least not single gene) causes predicts a moderate but still important yield from genetic testing. Our data for cerebellar malformations (CBLH-DWM) demonstrated a molecular diagnosis rate of $16 \%$ that supports both genetic and non-genetic factors, some of which predispose to vascular perfusion defects [Aldinger et al., 2019]. Data for PMG-SUB-PNH are not yet available, but we predict a similar modest rate that identifies some genes important for vascular development and function (i.e. TBX1, COL4A1, COL4A2) and others (i.e. DDX3X, GRIN1, GRIN2B) that support different mechanisms [Fry et al., 2018; Lennox et al., 2020; Platzer et al., 2017]. Thus, genetic testing may be indicated in twins with MCD, CBLH-DWM or BRD given an expected diagnostic rate in the range of $15-25 \%$.

\section{Summary}

Our data confirms the current large body of literature regarding twinning-associated disorders but goes much further as it expands the spectrum of brain malformations and disruptions seen in twins and strengthens data supporting prenatal vascular pathogenesis. We confirm that PMG is often seen in twins including discordant MZ twins and show that full thickness clefts lined by PMG (a.k.a. schizencephaly) comprise the severe end of a broad spectrum of MCD. We show that heterotopia - both SUB and PNH - are common in twins with structural abnormalities in brain and may be either posterior or anterior predominant. We show that both DWM and other common CBLH subtypes especially those associated with cerebellar asymmetry or clefts are 
seen in twins including discordant $\mathrm{MZ}$ twins and may co-occur with PMG-SUB-PNH. Based on results from our cohort and prior reports, we show that:

- The broad spectrum of twinning-associated brain malformations includes polymicrogyria, subcortical heterotopia and deep infolding, periventricular nodular heterotopia, common forms of cerebellar hypoplasia and classic Dandy-Walker malformation;

- The broad spectrum of twinning-associated brain disruption includes hydranencephaly, porencephaly, multicystic encephalomalacia, and less specific loss of white matter volume;

- The patterns of twinning-associated brain malformations and disruptions differ from the more common genetic subtypes because of the restricted patterns of MCD (PMG-SUB-PNH) and cerebellar malformations (DWM and common forms of CBLH), as well as the occurrence of asymmetry and clefts in both the cerebral hemispheres and cerebellum, features that should allow for suspicion of non-genetic causes in singletons with the same types of brain malformations and disruptions;

- The occurrence of intrauterine fetal demise (vanishing twin), twin-twin transfusion syndrome and intrauterine growth retardation are important risk factors for brain malformations and disruptions in twins (although the relative risk still seems small);

- Twinning-associated brain malformations and disruptions occur in both monozygotic and dizygotic twins as should be expected considering the high frequency of abnormal vascular connections seen in both $\mathrm{DZ}$ and $\mathrm{MZ}$ twin placentas;

This article is protected by copyright. All rights reserved. 
- The diverse data reviewed above collectively provide strong support for a prenatal vascular pathogenesis, defined broadly to include defects in vasculogenesis, diffuse or focal defects in vascular perfusion, and intracranial hemorrhage;

- The same prenatal vascular pathogenesis explains the occasional co-occurrence of these brain malformations and disruptions with other types of fetal disruption such as septo-optic dysplasia, amyoplasia, gastroschisis, and other patterns noted above; and finally

- $\quad$ Based on these data we hypothesize that prenatal vascular pathogenesis is the most likely explanation for the modest molecular diagnosis rate for PMG, SUB, PNH, CBLH and DWM in singletons.

Our data and analysis bring our understanding of the pathogenesis of these malformations and disruptions full circle. Reports prior to the past decade suggested a vascular pathogenesis, at least for PMG [Barkovich et al., 1995; Crome, 1952; Crome and France, 1959; de Leon, 1972; Ferrer, 1984; Ferrer and Catala, 1991; Levine et al., 1974; Richman et al., 1974; Williams et al., 1976]. Reports over the past decade have described a gradually increasing number of single genes with PMG, PNH or both [Broix et al., 2016; Fox et al., 1998; Fry et al., 2018; Heinzen et al., 2018; Jurkiewicz et al., 2017; Lennox et al., 2020; Pagnamenta et al., 2015; Platzer et al., 2017; Ravenscroft et al., 2016]. Our data and analysis strongly support both non genetic and genetic factors in the pathogenesis of twinning-associated malformation and disruptions, with a subset of genetic causes causing or predisposing to prenatal vascular disruption.

\section{ACKNOWLEDGEMENTS}

This article is protected by copyright. All rights reserved. 
We thank the children and their families as well as many referring physicians for their important contributions to this study. This study was funded by the US National Institutes of Health under NINDS grant numbers 5R01NS050375 to WBD, K08NS092898 to GMM, and R24HD000836 to IAG. Additional funding was provided by The Dandy-Walker Alliance and The Philly Baer Foundation. The content is solely the responsibility of the authors and does not necessarily represent the official views of the funding sources.

\section{CONFLICTS OF INTEREST}

The authors have no conflicts of interest to declare.

\section{AUTHOR CONTRIBUTIONS}

Kaylee B. Park: study design, data acquisition, data analysis, manuscript preparation and revisions; Teresa Chapman: analysis of brain imaging studies; Kimberly A. Aldinger: data acquisition and analysis; Ghayda M Mirzaa: clinical evaluation; Jordan Zeiger: data acquisition; Anita Beck: clinical evaluation; Ian A. Glass: clinical evaluation; Robert F. Hevner: analysis of neuropathology data; Anna C. Jansen: clinical evaluation; Desiree A. Marshall: analysis of neuropathology data; Renske Oegema: clinical evaluation; Elena Parrini: clinical evaluation; Russell P. Saneto: clinical evaluation; Cynthia J. Curry: clinical evaluation, critical review of the manuscript; Judith G. Hall: data analysis, critical review of the manuscript; Renzo Guerrini: clinical evaluation; Richard J. Leventer: study design, data analysis, critical review of the manuscript; William B. Dobyns: study conception and design, data acquisition and analysis, 
clinical evaluation, analysis of brain imaging studies, construction of figures, manuscript preparation, manuscript preparation and critical review.

\section{DATA AVAILABILITY STATEMENT}

The data that supports the findings of this study are available in the Tables and Appendices of this article. Additional individual level data such as prenatal history and more complete brain imaging studies are available from the corresponding author on request for research purposes.

\section{ORCID}

Kimberly A. Aldinger https://orcid.org/0000-0002-5406-8911

Ghayda Mirzaa https://orcid.org/0000-0003-2648-7657

Anita E. Beck https://orcid.org/0000-0002-7965-0326

Anna C Jansen http://orcid.org/0000-0002-3835-2824

Judith G. Hall https://orcid.org/0000-0001-5062-491X

Renzo Guerrini https://orcid.org/0000-0002-7272-7079

William B. Dobyns https://orcid.org/0000-0002-7681-2844

\section{SUPPORTING INFORMATION}

The appendices may be found online in the Supporting Information section at the end of this article.

\section{REFERENCES}

This article is protected by copyright. All rights reserved. 
Abe T, Singer RJ, Marks MP, Kojima K, Watanabe M, Uchida M, Hayabuchi N. 1997. Arterial vascular abnormality accompanying cerebral cortical dysplasia. AJNR Am J Neuroradiol 18(1):144-6.

Adam AP, Curry CJ, Hall JG, Keppler-Noreuil KM, Adam MP, Dobyns WB. 2020. Recurrent constellations of embryonic malformations re-conceptualized as an overlapping group of disorders with shared pathogenesis. Am J Med Genet A.

Adegbite AL, Castille S, Ward S, Bajoria R. 2005. Prevalence of cranial scan abnormalities in preterm twins in relation to chorionicity and discordant birth weight. Eur J Obstet Gynecol Reprod Biol 119(1):47-55.

Aldinger KA, Timms AE, Thomson Z, Mirzaa GM, Bennett JT, Rosenberg AB, Roco CM, Hirano M, Abidi F, Haldipur P, Cheng CV, Collins S, Park K, Zeiger J, Overmann LM, Alkuraya FS, Biesecker LG, Braddock SR, Cathey S, Cho MT, Chung BHY, Everman DB, Zarate YA, Jones JR, Schwartz CE, Goldstein A, Hopkin RJ, Krantz ID, Ladda RL, Leppig KA, McGillivray BC, Sell S, Wusik K, Gleeson JG, Nickerson DA, Bamshad MJ, Gerrelli D, Lisgo SN, Seelig G, Ishak GE, Barkovich AJ, Curry CJ, Glass IA, Millen KJ, Doherty D, Dobyns WB. 2019. Redefining the Etiologic Landscape of Cerebellar Malformations. Am J Hum Genet 105(3):606-615.

Bankl H, Jellinger K. 1967. [Central nervous system injuries following fetal carbon monoxide poisoning]. Beitr Pathol Anat 135(3):350-76.

Barkovich AJ, Rowley H, Bollen A. 1995. Correlation of prenatal events with the development of polymicrogyria. AJNR Am J Neuroradiol 16(4 Suppl):822-7.

This article is protected by copyright. All rights reserved. 
Benbir G, Kara S, Yalcinkaya BC, Karhkaya G, Tuysuz B, Kocer N, Yalcinkaya C. 2011. Unilateral cerebellar hypoplasia with different clinical features. Cerebellum 10(1):49-60. Benda CE. 1954. The Dandy-Walker syndrome or the so-called atresia of the foramen of Magendie. J Neuropathol Exp Neurol 13(1):14-29.

Benirschke K. 1992. The contribution of placental anastomoses to prenatal twin damage. Hum Pathol 23(12):1319-20.

Bernardo S, Vinci V, Saldari M, Servadei F, Silvestri E, Giancotti A, Aliberti C, Porpora MG, Triulzi F, Rizzo G, Catalano C, Manganaro L. 2015. Dandy-Walker Malformation: is the 'tail sign' the key sign? Prenat Diagn 35(13):1358-64.

Broix L, Jagline H, E LI, Schmucker S, Drouot N, Clayton-Smith J, Pagnamenta AT, Metcalfe KA, Isidor B, Louvier UW, Poduri A, Taylor JC, Tilly P, Poirier K, Saillour Y, Lebrun N, Stemmelen T, Rudolf G, Muraca G, Saintpierre B, Elmorjani A, Deciphering Developmental Disorders s, Moise M, Weirauch NB, Guerrini R, Boland A, Olaso R, Masson C, Tripathy R, Keays D, Beldjord C, Nguyen L, Godin J, Kini U, Nischke P, Deleuze JF, Bahi-Buisson N, Sumara I, Hinckelmann MV, Chelly J. 2016. Mutations in the HECT domain of NEDD4L lead to AKT-mTOR pathway deregulation and cause periventricular nodular heterotopia. Nat Genet 48(11):1349-1358.

Burke JP, O'Keefe M, Bowell R. 1991. Optic nerve hypoplasia, encephalopathy, and neurodevelopmental handicap. Br J Ophthalmol 75(4):236-9.

Cavallin M, Mine M, Philbert M, Boddaert N, Lepage JM, Coste T, Lopez-Gonzalez V, SanchezSoler MJ, Ballesta-Martinez MJ, Remerand G, Pasquier L, Guet A, Chelly J, Lascelles K, Prieto-Morin C, Kossorotoff M, Tournier Lasserve E, Bahi-Buisson N. 2018. Further 
refinement of COL4A1 and COL4A2 related cortical malformations. Eur J Med Genet 61(12):765-772.

Charsar BA, Goldberg EM. 2017. Polymicrogyria and Intractable Epilepsy in Siblings With Knobloch Syndrome and Homozygous Mutation of COL18A1. Pediatr Neurol 76:91-92.

Chugh AJ, Shahid A, Manjila S, Gulati D, Bambakidis NC. 2017. Pial Arteriovenous Fistula and Capillary Malformation-Arteriovenous Malformation Associated with RASA1 Mutation: 2 Pediatric Cases with Successful Surgical Management. Pediatr Neurosurg 52(4):261-267.

Cioffi S, Martucciello S, Fulcoli FG, Bilio M, Ferrentino R, Nusco E, Illingworth E. 2014. Tbx1 regulates brain vascularization. Hum Mol Genet 23(1):78-89.

Collins DL, Kimura K, Morgan A, Johnson DG, Leonard C, Jones MC. 1986. Multiple intestinal atresia and amyoplasia congenita in four unrelated infants: a new association. J Pediatr Surg 21(4):331-3.

Corbett MA, Turner SJ, Gardner A, Silver J, Stankovich J, Leventer RJ, Derry CP, Carroll R, Ha T, Scheffer IE, Bahlo M, Jackson GD, Mackey DA, Berkovic SF, Gecz J. 2017. Familial epilepsy with anterior polymicrogyria as a presentation of COL18A1 mutations. Eur J Med Genet 60(8):437-443.

Cragan JD, Martin ML, Waters GD, Khoury MJ. 1994. Increased risk of small intestinal atresia among twins in the United States. Arch Pediatr Adolesc Med 148(7):733-9.

Crome L. 1952. Microgyria. J Pathol Bacteriol 64(3):479-95.

Crome L, France NE. 1959. Microgyria and cytomegalic inclusion disease in infancy. J Clin Pathol 12:427-34.

This article is protected by copyright. All rights reserved. 
Curry CJ, Lammer EJ, Nelson V, Shaw GM. 2005. Schizencephaly: heterogeneous etiologies in a population of 4 million California births. Am J Med Genet A 137(2):181-9.

Dale ST, Coleman LT. 2002. Neonatal alloimmune thrombocytopenia: antenatal and postnatal imaging findings in the pediatric brain. AJNR Am J Neuroradiol 23(9):1457-65.

Dawson AL, Tinker SC, Jamieson DJ, Hobbs CA, Berry RJ, Rasmussen SA, Anderka M, Keppler-Noreuil KM, Lin AE, Reefhuis J, National Birth Defects Prevention S. 2016. Twinning and major birth defects, National Birth Defects Prevention Study, 1997-2007. J Epidemiol Community Health 70(11):1114-1121.

de Leon GA. 1972. Observations on cerebral and cerebellar microgyria. Acta Neuropathol 20(4):278-87.

De Paepe ME, Luks FI. 2013. What-and why-the pathologist should know about twin-to-twin transfusion syndrome. Pediatr Dev Pathol 16(4):237-51.

Dekaban AS. 1965. Large defects in cerebral hemispheres associated with cortical dysgenesis. J Neuropathol Exp Neurol 24(3):512-30.

Dostanic T, Sustersic B, Paro-Panjan D. 2018. Developmental outcome in a group of twins: Relation to perinatal factors and general movements. Eur J Paediatr Neurol 22(4):682-689. Engle WA, American Academy of Pediatrics Committee on F, Newborn. 2004. Age terminology during the perinatal period. Pediatrics 114(5):1362-4.

Faivre L, Amiel J, Ouachee-Chardin M, Genevieve D, Munnich A, Cormier-Daire V, Monceaux F, Teillac D. 2002. Septo-optic dysplasia and digital anomalies: another observation. Am J Med Genet 108(3):247-8.

This article is protected by copyright. All rights reserved. 
Feldkamp ML, Carey JC, Sadler TW. 2007. Development of gastroschisis: review of hypotheses, a novel hypothesis, and implications for research. Am J Med Genet A $143 \mathrm{~A}(7): 639-52$.

Fellman J, Eriksson AW. 2006. Weinberg's differential rule reconsidered. Hum Biol 78(3):25375.

Ferrer I. 1984. A Golgi analysis of unlayered polymicrogyria. Acta Neuropathol 65(1):69-76.

Ferrer I, Catala I. 1991. Unlayered polymicrogyria: structural and developmental aspects. Anat Embryol (Berl) 184(5):517-28.

Fitzgerald B. 2018. Histopathological examination of the placenta in twin pregnancies. APMIS 126(7):626-637.

Folkerth RD, McLaughlin ME, Levine D. 2001. Organizing posterior fossa hematomas simulating developmental cysts on prenatal imaging: report of 3 cases. J Ultrasound Med 20(11):1233-40.

Fox JW, Lamperti ED, Eksioglu YZ, Hong SE, Feng Y, Graham DA, Scheffer IE, Dobyns WB, Hirsch BA, Radtke RA, Berkovic SF, Huttenlocher PR, Walsh CA. 1998. Mutations in filamin 1 prevent migration of cerebral cortical neurons in human periventricular heterotopia. Neuron 21(6):1315-25.

Fry AE, Fawcett KA, Zelnik N, Yuan H, Thompson BAN, Shemer-Meiri L, Cushion TD, Mugalaasi H, Sims D, Stoodley N, Chung SK, Rees MI, Patel CV, Brueton LA, Layet V, Giuliano F, Kerr MP, Banne E, Meiner V, Lerman-Sagie T, Helbig KL, Kofman LH, Knight KM, Chen W, Kannan V, Hu C, Kusumoto H, Zhang J, Swanger SA, Shaulsky GH, Mirzaa GM, Muir AM, Mefford HC, Dobyns WB, Mackenzie AB, Mullins JGL, Lemke JR, Bahi- 
Buisson N, Traynelis SF, lago HF, Pilz DT. 2018. De novo mutations in GRIN1 cause extensive bilateral polymicrogyria. Brain 141(3):698-712.

Garvin J, Sampath V, Karody VR. 2016. Gastroschisis Complicated by Septo-Optic Dysplasia: Two Distinct Anomalies with a Common Origin. AJP Rep 6(1):e15-7.

Glinianaia SV, Rankin J, Wright C. 2008. Congenital anomalies in twins: a register-based study. Hum Reprod 23(6):1306-11.

Guerrini R, Dobyns WB. 2014. Malformations of cortical development: clinical features and genetic causes. Lancet Neurol 13(7):710-26.

Guerrini R, Dubeau F, Dulac O, Barkovich AJ, Kuzniecky R, Fett C, Jones-Gotman M, Canapicchi R, Cross H, Fish D, Bonanni P, Jambaque I, Andermann F. 1997. Bilateral parasagittal parietooccipital polymicrogyria and epilepsy. Ann Neurol 41(1):65-73.

Hall JG. 1996. Twins and twinning. Am J Med Genet 61(3):202-4.

Hall JG. 2003. Twinning. Lancet 362(9385):735-43.

Hall JG, Aldinger KA, Tanaka KI. 2014. Amyoplasia revisited. Am J Med Genet A 164A(3):70030.

Haller JS, Wolpert SM, Rabe EF, Hills JR. 1971. Cystic lesions of the posterior fossa in infants: a comparison of the clinical, radiological, and pathological findings in Dandy-Walker syndrome and extra-axial cysts. Neurology 21(5):494-506.

Hallervorden J. 1949. Uber eine Kohlenoxydvergiftung im Fetalleben mit Entwicklungsstörung der Hirnrinde. All Z Psychiatr 124:289-298.

Harrison IM, Brosnahan D, Phelan E, Fitzgerald RJ, Reardon W. 2004. Septo-optic dysplasia with digital anomalies--a recurrent pattern syndrome. Am J Med Genet A 131(1):82-5.

This article is protected by copyright. All rights reserved. 
Hayashi N, Tsutsumi Y, Barkovich AJ. 2002. Morphological features and associated anomalies of schizencephaly in the clinical population: detailed analysis of MR images. Neuroradiology 44(5):418-27.

Heinzen EL, O'Neill AC, Zhu X, Allen AS, Bahlo M, Chelly J, Chen MH, Dobyns WB, Freytag S, Guerrini R, Leventer RJ, Poduri A, Robertson SP, Walsh CA, Zhang M, Epi KC, Epilepsy Phenome/Genome P. 2018. De novo and inherited private variants in MAP1B in periventricular nodular heterotopia. PLoS Genet 14(5):e1007281.

Hess CP, Fullerton HJ, Metry DW, Drolet BA, Siegel DH, Auguste KI, Gupta N, Haggstrom AN, Dowd CF, Frieden IJ, Barkovich AJ. 2010. Cervical and intracranial arterial anomalies in 70 patients with PHACE syndrome. AJNR Am J Neuroradiol 31(10):1980-6.

Hildebrandt T, Powell T. 2002. Repeated antenatal intracranial haemorrhage: magnetic resonance imaging in a fetus with alloimmune thrombocytopenia. Arch Dis Child Fetal Neonatal Ed 87(3):F222-3.

Hintz SR, Barnes PD, Bulas D, Slovis TL, Finer NN, Wrage LA, Das A, Tyson JE, Stevenson DK, Carlo WA, Walsh MC, Laptook AR, Yoder BA, Van Meurs KP, Faix RG, Rich W, Newman NS, Cheng H, Heyne RJ, Vohr BR, Acarregui MJ, Vaucher YE, Pappas A, PeraltaCarcelen M, Wilson-Costello DE, Evans PW, Goldstein RF, Myers GJ, Poindexter BB, McGowan EC, Adams-Chapman I, Fuller J, Higgins RD, Health SSGotEKSNIoC, Human Development Neonatal Research N. 2015. Neuroimaging and neurodevelopmental outcome in extremely preterm infants. Pediatrics 135(1):e32-42.

Hung PC, Wang HS, Yeh YS, Lui TN, Lee ST. 1996. Coexistence of schizencephaly and intracranial arteriovenous malformation in an infant. AJNR Am J Neuroradiol 17(10):1921-2. 
Jahanfar S, Lim K. 2018. Is there a relationship between fetal sex and placental pathological characteristics in twin gestations? BMC Pregnancy Childbirth 18(1):285.

Jenkyn LR, Roberts DW, Merlis AL, Rozycki AA, Nordgren RE. 1981. Dandy-Walker malformation in identical twins. Neurology 31(3):337-41.

Johnson MD, Gentry LR, Rice GM, Mount DL. 2010. A case of congenitally absent left internal carotid artery: vascular malformations in 22q11.2 deletion syndrome. Cleft Palate Craniofac J 47(3):314-7.

Jones KL, Weiss LA, Hagey LR, Gonzalez V, Benirschke K, Chambers CD. 2013. Altered lipid metabolism in gastroschisis: a novel hypothesis. Am J Med Genet A 161A(8):1860-5.

Jordan MA, Montezuma SR. 2015. Septo-optic dysplasia associated with congenital persistent fetal vasculature, retinal detachment, and gastroschisis. Retin Cases Brief Rep 9(2):123-6.

Jurkiewicz E, Dunin-Wasowicz D, Gieruszczak-Bialek D, Malczyk K, Guerrero K, Gutierrez M, Tran L, Bernard G. 2017. Recessive Mutations in POLR3B Encoding RNA Polymerase III Subunit Causing Diffuse Hypomyelination in Patients with 4H Leukodystrophy with Polymicrogyria and Cataracts. Clin Neuroradiol 27(2):213-220.

Kamien B, Zankl A, Gabbett M. 2010. Septo-optic dysplasia and associations with amyoplasia and gastroschisis. Birth Defects Res A Clin Mol Teratol 88(6):497-501.

Keren B, Suzuki OT, Gerard-Blanluet M, Bremond-Gignac D, Elmaleh M, Titomanlio L, Delezoide AL, Passos-Bueno MR, Verloes A. 2007. CNS malformations in Knobloch syndrome with splice mutation in COL18A1 gene. Am J Med Genet A 143A(13):1514-8.

This article is protected by copyright. All rights reserved. 
Klostranec JM, Brinjikji W, Mathur S, Orru E, Andrade DM, Krings T. 2019a. Cerebral Corticoarterial Malformations : A Case Series of Unilateral Polymicrogyria and Ipsilateral Arterial Dysplasia. Clin Neuroradiol.

Klostranec JM, Chen L, Mathur S, McDonald J, Faughnan ME, Ratjen F, Krings T. 2019b. A theory for polymicrogyria and brain arteriovenous malformations in HHT. Neurology 92(1):34-42.

Kontopoulos EV, Quintero RA, Salihu HM, Bornick PW, Allen MH. 2008. Dandy-Walker syndrome and monochorionic twins: insight into a possible etiological mechanism. J Matern Fetal Neonatal Med 21(11):839-42.

Kosinska-Kaczynska K, Szymusik I, Bomba-Opon D, Olejek A, Slawska H, Zimmer M, Pomorski M, Breborowicz G, Drews K, Seremak-Mrozikiewicz A, Szymankiewicz M, Pikula T, Oleszczuk J, Patro-Malysza J, Marciniak B, Wielgos M. 2016. Perinatal outcome according to chorionicity in twins - a Polish multicenter study. Ginekol Pol 87(5):384-9.

Koul RL, Chacko A, Leven HO. 2000. Dandy-Walker syndrome in association with neurofibromatosis in monozygotic twins. Saudi Med J 21(4):390-2.

Kuban KC, Teele RL, Wallman J. 1989. Septo-optic-dysplasia-schizencephaly. Radiographic and clinical features [see comments]. Pediatr Radiol 19(3):145-50.

Kuijpers RW, van den Anker JN, Baerts W, von dem Borne AE. 1994. A case of severe neonatal thrombocytopenia with schizencephaly associated with anti-HPA-1b and anti-HPA2a. Br J Haematol 87(3):576-9.

Larroche JC, Girard N, Narcy F, Fallet C. 1994. Abnormal cortical plate (polymicrogyria), heterotopias and brain damage in monozygous twins. Biol Neonate 65(6):343-52.

This article is protected by copyright. All rights reserved. 
Lennon K. 2002. Identical twins presenting with Dandy-Walker malformation and twin-twin transfusion. Journal of Diagnostic Medical Sonography 18(5):328-331.

Lennox AL, Hoye ML, Jiang R, Johnson-Kerner BL, Suit LA, Venkataramanan S, Sheehan CJ, Alsina FC, Fregeau B, Aldinger KA, Moey C, Lobach I, Afenjar A, Babovic-Vuksanovic D, Bézieau S, Blackburn PR, Bunt J, Burglen L, Campeau PM, Charles P, Chung BHY, Cogné B, Curry C, D'Agostino MD, Di Donato N, Faivre L, Héron D, Innes AM, Isidor B, Keren B, Kimball A, Klee EW, Kuentz P, Küry S, Martin-Coignard D, Mirzaa G, Mignot C, Miyake N, Matsumoto N, Fujita A, Nava C, Nizon M, Rodriguez D, Blok LS, Thauvin-Robinet C, Thevenon J, Vincent M, Ziegler A, Dobyns W, Richards LJ, Barkovich AJ, Floor SN, Silver DL, Sherr EH. 2020. Pathogenic DDX3X Mutations Impair RNA Metabolism and Neurogenesis during Fetal Cortical Development. Neuron 106(3):404-420.e8.

Leventer RJ, Jansen A, Pilz DT, Stoodley N, Marini C, Dubeau F, Malone J, Mitchell LA, Mandelstam S, Scheffer IE, Berkovic SF, Andermann F, Andermann E, Guerrini R, Dobyns WB. 2010. Clinical and imaging heterogeneity of polymicrogyria: a study of 328 patients. Brain 133(Pt 5):1415-27.

Levine DN, Fisher MA, Caviness VS, Jr. 1974. Porencephaly with microgyria: a pathologic study. Acta Neuropathol 29(2):99-113.

Li DZ, Liao C. 2009. Monozygotic twins discordant for Dandy-Walker malformation. Fetal Diagn Ther 25(1):141-3.

Limperopoulos C, Folkerth R, Barnewolt CE, Connolly S, Du Plessis AJ. 2010. Posthemorrhagic cerebellar disruption mimicking Dandy-Walker malformation: fetal imaging and neuropathology findings. Semin Pediatr Neurol 17(1):75-81.

This article is protected by copyright. All rights reserved. 
Lindsay EA, Vitelli F, Su H, Morishima M, Huynh T, Pramparo T, Jurecic V, Ogunrinu G, Sutherland HF, Scambler PJ, Bradley A, Baldini A. 2001. Tbx1 haploinsufficieny in the DiGeorge syndrome region causes aortic arch defects in mice. Nature 410(6824):97-101. Livinec F, Ancel PY, Marret S, Arnaud C, Fresson J, Pierrat V, Roze JC, Escande B, Thiriez G, Larroque B, Kaminski M, Epipage G. 2005. Prenatal risk factors for cerebral palsy in very preterm singletons and twins. Obstet Gynecol 105(6):1341-7.

Lopriore E, Te Pas AB, Steggerda SJ, Kanhai HH, Marijt EW, Brand A, Walther FJ, van WezelMeijler G. 2007. Polymicrogyria in a neonate with severe autoimmune thrombocytopenia: rare coincidence or related disorder? Prenat Diagn 27(1):87-9.

Lubinsky M. 2012. Hypothesis: Estrogen related thrombosis explains the pathogenesis and epidemiology of gastroschisis. Am J Med Genet A 158A(4):808-11.

Luu TM, Vohr B. 2009. Twinning on the brain: the effect on neurodevelopmental outcomes. Am J Med Genet C Semin Med Genet 151C(2):142-7.

Mancini J, Lethel V, Hugonenq C, Chabrol B. 2001. Brain injuries in early foetal life: consequences for brain development. Dev Med Child Neurol 43(1):52-5.

Massoud M, Cagneaux M, Garel C, Varene N, Moutard ML, Billette T, Benezit A, Rougeot C, Jouannic JM, Massardier J, Gaucherand P, Desportes V, Guibaud L. 2014. Prenatal unilateral cerebellar hypoplasia in a series of 26 cases: significance and implications for prenatal diagnosis. Ultrasound Obstet Gynecol 44(4):447-54.

Mastroiacovo P, Castilla EE, Arpino C, Botting B, Cocchi G, Goujard J, Marinacci C, Merlob P, Metneki J, Mutchinick O, Ritvanen A, Rosano A. 1999. Congenital malformations in twins: an international study. Am J Med Genet 83(2):117-24.

This article is protected by copyright. All rights reserved. 
Miller SP, Shevell MI, Patenaude Y, Poulin C, O'Gorman AM. 2000. Septo-optic dysplasia plus: A spectrum of malformations of cortical development [In Process Citation]. Neurology 54(8):1701-3.

Mochizuki K, Shinkai M, Ohhama Y, Take H, Kitagawa N, Honda S, Hirata Y, Ishikawa H. 2010. Multiple intestinal atresia and congenital bilateral perisylvian syndrome in a surviving monochorionic twin with intrauterine death of the co-twin. J Pediatr Surg 45(8):E7-8.

Myrianthopoulos NC. 1976. Congenital malformations in twins. Acta Genet Med Gemellol (Roma) 25:331-5.

Oegema R, Barkovich AJ, Mancini GMS, Guerrini R, Dobyns WB. 2019. Subcortical heterotopic gray matter brain malformations: Classification study of 107 individuals. Neurology 93(14):e1360-e1373.

Opitz JM, Feldkamp ML, Botto LD. 2019. An evolutionary and developmental biology approach to gastroschisis. Birth Defects Res 111(6):294-311.

Ortibus E, Lopriore E, Deprest J, Vandenbussche FP, Walther FJ, Diemert A, Hecher K, Lagae L, De Cock P, Lewi PJ, Lewi L. 2009. The pregnancy and long-term neurodevelopmental outcome of monochorionic diamniotic twin gestations: a multicenter prospective cohort study from the first trimester onward. Am J Obstet Gynecol 200(5):494 e1-8.

Pagnamenta AT, Howard MF, Wisniewski E, Popitsch N, Knight SJ, Keays DA, Quaghebeur G, Cox H, Cox P, Balla T, Taylor JC, Kini U. 2015. Germline recessive mutations in PI4KA are associated with perisylvian polymicrogyria, cerebellar hypoplasia and arthrogryposis. Hum Mol Genet 24(13):3732-41.

This article is protected by copyright. All rights reserved. 
Pagon RA, Stephan MJ. 1984. Septo-optic dysplasia with digital anomalies. J Pediatr 105(6):966-8.

Painter JN, Medland SJ, Montgomery GW, Hall JG. 2013. Twins and twinning. In: Rimoin DL, Pyeritz RE, Korf B, editors. Emery and Rimoin's Principles and Practice of Medical Genetics. 6th ed: Academic Press. p 1-20.

Paisan-Ruiz C, Scopes G, Lee P, Houlden H. 2009. Homozygosity mapping through whole genome analysis identifies a COL18A1 mutation in an Indian family presenting with an autosomal recessive neurological disorder. Am J Med Genet B Neuropsychiatr Genet $150 B(7): 993-7$.

Palagallo GJ, McWilliams SR, Sekarski LA, Sharma A, Goyal MS, White AJ. 2017. The Prevalence of Malformations of Cortical Development in a Pediatric Hereditary Hemorrhagic Telangiectasia Population. AJNR Am J Neuroradiol 38(2):383-386.

Parrini E, Ramazzotti A, Dobyns WB, Mei D, Moro F, Veggiotti P, Marini C, Brilstra EH, Dalla Bernardina B, Goodwin L, Bodell A, Jones MC, Nangeroni M, Palmeri S, Said E, Sander JW, Striano P, Takahashi Y, Van Maldergem L, Leonardi G, Wright M, Walsh CA, Guerrini R. 2006. Periventricular heterotopia: phenotypic heterogeneity and correlation with Filamin A mutations. Brain 129(Pt 7):1892-906.

Patel S, Randolph LM, Benirschke K, Llanes A, Yedigarova L, Chmait RH. 2012. Prevalence of noncardiac structural anomalies in twin-twin transfusion syndrome. J Ultrasound Med 31(4):555-60.

Pati S, Helmbrecht GD. 1994. Congenital schizencephaly associated with in utero warfarin exposure. Reprod Toxicol 8(2):115-20.

This article is protected by copyright. All rights reserved. 
Pichiecchio A, Decio A, Di Perri C, Parazzini C, Rossi A, Signorini S. 2016. "Acquired" DandyWalker malformation and cerebellar hemorrhage: Usefulness of serial MRI. Eur J Paediatr Neurol 20(1):188-91.

Platzer K, Yuan H, Schutz H, Winschel A, Chen W, Hu C, Kusumoto H, Heyne HO, Helbig KL, Tang S, Willing MC, Tinkle BT, Adams DJ, Depienne C, Keren B, Mignot C, Frengen E, Stromme P, Biskup S, Docker D, Strom TM, Mefford HC, Myers CT, Muir AM, LaCroix A, Sadleir L, Scheffer IE, Brilstra E, van Haelst MM, van der Smagt JJ, Bok LA, Moller RS, Jensen UB, Millichap JJ, Berg AT, Goldberg EM, De Bie I, Fox S, Major P, Jones JR, Zackai EH, Abou Jamra R, Rolfs A, Leventer RJ, Lawson JA, Roscioli T, Jansen FE, Ranza E, Korff CM, Lehesjoki AE, Courage C, Linnankivi T, Smith DR, Stanley C, Mintz M, McKnight D, Decker A, Tan WH, Tarnopolsky MA, Brady LI, Wolff M, Dondit L, Pedro HF, Parisotto SE, Jones KL, Patel AD, Franz DN, Vanzo R, Marco E, Ranells JD, Di Donato N, Dobyns WB, Laube B, Traynelis SF, Lemke JR. 2017. GRIN2B encephalopathy: novel findings on phenotype, variant clustering, functional consequences and treatment aspects. J Med Genet 54(7):460-470.

Poretti A, Huisman TA, Cowan FM, Del Giudice E, Jeannet PY, Prayer D, Rutherford MA, du Plessis AJ, Limperopoulos C, Boltshauser E. 2009. Cerebellar cleft: confirmation of the neuroimaging pattern. Neuropediatrics 40(5):228-33.

Poretti A, Leventer RJ, Cowan FM, Rutherford MA, Steinlin M, Klein A, Scheer I, Huisman TA, Boltshauser E. 2008. Cerebellar cleft: a form of prenatal cerebellar disruption. Neuropediatrics 39(2):106-12.

This article is protected by copyright. All rights reserved. 
Poretti A, Limperopoulos C, Roulet-Perez E, Wolf NI, Rauscher C, Prayer D, Muller A, Weissert M, Kotzaeridou U, Du Plessis AJ, Huisman TA, Boltshauser E. 2010. Outcome of severe unilateral cerebellar hypoplasia. Dev Med Child Neurol 52(8):718-24.

Ravenscroft G, Di Donato N, Hahn G, Davis MR, Craven PD, Poke G, Neas KR, Neuhann TM, Dobyns WB, Laing NG. 2016. Recurrent de novo BICD2 mutation associated with arthrogryposis multiplex congenita and bilateral perisylvian polymicrogyria. Neuromuscul Disord 26(11):744-748.

Reeder MR, Botto LD, Keppler-Noreuil KM, Carey JC, Byrne JL, Feldkamp ML, National Birth Defects Prevention S. 2015. Risk factors for Dandy-Walker malformation: a populationbased assessment. Am J Med Genet A 167A(9):2009-16.

Reid CO, Hall JG, Anderson C, Bocian M, Carey J, Costa T, Curry C, Greenberg F, Horton W, Jones M, et al. 1986. Association of amyoplasia with gastroschisis, bowel atresia, and defects of the muscular layer of the trunk. Am J Med Genet 24(4):701-10.

Richman DP, Stewart RM, Caviness VS, Jr. 1974. Cerebral microgyria in a 27-week fetus: an architectonic and topographic analysis. J Neuropathol Exp Neurol 33(3):374-84.

Rittler M, Vauthay L, Mazzitelli N. 2013. Gastroschisis is a defect of the umbilical ring: evidence from morphological evaluation of stillborn fetuses. Birth Defects Res A Clin Mol Teratol 97(4):198-209.

Robin NH, Taylor CJ, McDonald-McGinn DM, Zackai EH, Bingham P, Collins KJ, Earl D, Gill D, Granata T, Guerrini R, Katz N, Kimonis V, Lin JP, Lynch DR, Mohammed SN, Massey RF, McDonald M, Rogers RC, Splitt M, Stevens CA, Tischkowitz MD, Stoodley N, Leventer RJ, 
Pilz DT, Dobyns WB. 2006. Polymicrogyria and deletion 22q11.2 syndrome: window to the etiology of a common cortical malformation. Am J Med Genet A 140(22):2416-25.

Scheller JM, Nelson KB. 1992. Twinning and neurologic morbidity. Am J Dis Child 146(9):11103.

Schinzel AA, Smith DW, Miller JR. 1979. Monozygotic twinning and structural defects. J Pediatr 95(6):921-30.

Shen EY. 1989. Dandy-Walker syndrome: follow up of an unoperated case and her identical twin. Zhonghua Min Guo Xiao Er Ke Yi Xue Hui Za Zhi 30(6):422-7.

Shenoy MU, Marlow N, Stewart RJ. 1999. Amyoplasia congenita and intestinal atresia: a common etiology. Acta Paediatr 88(12):1405-6.

Sherer DM, Sokolovski M, Dalloul M, Santoso P, Zigalo A, Abulafia O. 2004. Fetal DandyWalker malformation complicated by late third-trimester unilateral intraventricular hemorrhage. J Ultrasound Med 23(6):873-6.

Shiohama T, Ando R, Fujii K, Mukai H, Naruke Y, Sugita K, Kato E, Shimojo N. 2017. An Acquired Form of Dandy-Walker Malformation with Enveloping Hemosiderin Deposits. Case Rep Pediatr 2017:3861608.

Shue EH, Soares B, Courtier J, Hogue J, Shimotake T, MacKenzie TC. 2012. Type IV intestinal atresia, congenital bilateral perisylvian syndrome, and chronic pulmonary hypertension secondary to multiple vascular disruption syndrome in a monochorionic twin. J Pediatr Surg 47(10):1938-42.

This article is protected by copyright. All rights reserved. 
Spranger J, Benirschke K, Hall JG, Lenz W, Lowry RB, Opitz JM, Pinsky L, Schwarzacher HG, Smith DW. 1982. Errors of morphogenesis: concepts and terms. Recommendations of an international working group. J Pediatr 100(1):160-5.

Squier W, Jansen A. 2010. Abnormal development of the human cerebral cortex. J Anat 217(4):312-23.

Steiner JE, McCoy GN, Hess CP, Dobyns WB, Metry DW, Drolet BA, Maheshwari M, Siegel DH. 2018. Structural malformations of the brain, eye, and pituitary gland in PHACE syndrome. Am J Med Genet A 176(1):48-55.

Steiner JI, Fink AM, Berkowitz RG. 2013. Magnetic resonance imaging findings in pediatric bilateral vocal fold dysfunction. Ann Otol Rhinol Laryngol 122(7):417-20.

Stevens CA, Dobyns WB. 2004. Septo-optic dysplasia and amniotic bands: further evidence for a vascular pathogenesis. Am J Med Genet A 125A(1):12-6.

Stransky C, Basta M, McDonald-McGinn DM, Solot CB, Drummond D, Zackai E, LaRossa D, Kirschner R, Jackson O. 2015. Perioperative risk factors in patients with 22q11.2 deletion syndrome requiring surgery for velopharyngeal dysfunction. Cleft Palate Craniofac J 52(2):183-91.

Suchet IB. 1994. Schizencephaly: antenatal and postnatal assessment with colour-flow Doppler imaging. Can Assoc Radiol J 45(3):193-200.

Sugama S, Kusano K. 1994. Monozygous twin with polymicrogyria and normal co-twin. Pediatr Neurol 11(1):62-3.

This article is protected by copyright. All rights reserved. 
Sullivan K, Croitoru D, Casella S, Hartman T, Edwards W. 2018. A case report of an infant with both left-sided gastroschisis and septo-optic dysplasia and literature review: possible shared etiology? J Pediatr Neonatal Care 8(3):139-141.

Tarui T, Khwaja OS, Estroff JA, Robinson JN, Gregas MC, Grant PE. 2012. Altered fetal cerebral and cerebellar development in twin-twin transfusion syndrome. AJNR Am J Neuroradiol 33(6):1121-6.

Torfs CP, Katz EA, Bateson TF, Lam PK, Curry CJ. 1996. Maternal medications and environmental exposures as risk factors for gastroschisis. Teratology 54(2):84-92.

Torfs CP, Velie EM, Oechsli FW, Bateson TF, Curry CJ. 1994. A population-based study of gastroschisis: demographic, pregnancy, and lifestyle risk factors. Teratology 50(1):44-53.

Tosello B, Garbi A, Blanc J, Lorthe E, Foix-L'Helias L, D'Ercole C, Winer N, Subtil D, Goffinet F, Kayem G, Resseguier N, Gire C, Group E-OW. 2020. The impact of chorionicity on pregnancy outcome and neurodevelopment at 2 years old among twins born preterm: the EPIPAGE-2 cohort study. BJOG.

Van Bogaert P, Donner C, David P, Rodesch F, Avni EF, Szliwowski HB. 1996. Congenital bilateral perisylvian syndrome in a monozygotic twin with intra-uterine death of the co-twin. Dev Med Child Neurol 38(2):166-70.

Werler MM, Mitchell AA, Moore CA, Honein MA, National Birth Defects Prevention S. 2009. Is there epidemiologic evidence to support vascular disruption as a pathogenesis of gastroschisis? Am J Med Genet A 149A(7):1399-406.

Werler MM, Sheehan JE, Mitchell AA. 2002. Maternal medication use and risks of gastroschisis and small intestinal atresia. Am J Epidemiol 155(1):26-31.

This article is protected by copyright. All rights reserved. 
Williams RS, Ferrante RJ, Caviness VS, Jr. 1976. The cellular pathology of microgyria. A Golgi analysis. Acta Neuropathol 36(3):269-83.

Wong HS, Kidd A, Zuccollo J, Parker S, Richardson V, Tait J, Pringle KC. 2009. A case of amyoplasia in a monochorionic twin pregnancy: a sequela from twin-twin transfusion syndrome? Fetal Diagn Ther 25(1):31-5.

Yamanouchi H, Ota T, Imataka G, Hagiwara Y, Nakagawa E, Eguchi M. 2002. Congenital bilateral perisylvian syndrome associated with congenital constriction band syndrome. J Child Neurol 17(6):448-50.

Yuksel A, Batukan C. 2003. Fetal cerebellar hemorrhage in a severely growth-restricted fetus: natural history and differential diagnosis from Dandy-Walker malformation. Ultrasound Obstet Gynecol 22(2):178-81.

Zagaglia S, Selch C, Nisevic JR, Mei D, Michalak Z, Hernandez-Hernandez L, Krithika S, Vezyroglou K, Varadkar SM, Pepler A, Biskup S, Leao M, Gartner J, Merkenschlager A, Jaksch M, Moller RS, Gardella E, Kristiansen BS, Hansen LK, Vari MS, Helbig KL, Desai S, Smith-Hicks CL, Hino-Fukuyo N, Talvik T, Laugesaar R, Ilves P, Ounap K, Korber I, Hartlieb T, Kudernatsch M, Winkler P, Schimmel M, Hasse A, Knuf M, Heinemeyer J, Makowski C, Ghedia S, Subramanian GM, Striano P, Thomas RH, Micallef C, Thom M, Werring DJ, Kluger GJ, Cross JH, Guerrini R, Balestrini S, Sisodiya SM. 2018. Neurologic phenotypes associated with COL4A1/2 mutations: Expanding the spectrum of disease. Neurology 91(22):e2078-e2088.

This article is protected by copyright. All rights reserved. 
Zhang XR, Liu J, Zeng CM. 2013. Perinatal risk factors and neonatal complications in discordant twins admitted to the neonatal intensive care unit. Chin Med J (Engl) 126(5):8459.

This article is protected by copyright. All rights reserved. 
TABLES

(separate file)

This article is protected by copyright. All rights reserved. 


\section{FIGURE LEGENDS}

Figure 1. Graphical demonstration of malformation-disruption subgroups and zygosity data. A pie chart $(A)$ shows the relative proportions of different subgroups defined in this series. $A$ bar graph (B) shows differences in the pattern of zygosity between this series and the literature cohort, with this series having a much larger proportion of DZ twins. Abbreviations as in text, except UZ, unknown zygosity.

Figure 2. Neuropathology from an MZ twin (LP93-085a2) that died at 23-weeks-gestation, several weeks after death of his male cotwin $X X$

Figure 3. Brain imaging and neuropathology from a discordant MZ twin girl (LP97-138). Low resolution brain MRI obtained in 1997 shows mildly low forehead and thin corpus callosum $(A)$, severe loss of volume of cerebral hemispheres more severe posteriorly and associated with enlarged extra-axial spaces, near diffuse irregular gyral pattern with microgyri more severe over posterior regions, near contiguous abnormal bright T2 signal consistent with white matter injury, and moderately enlarged lateral ventricles (B-C). On gross exam at autopsy, the brain was small with sunken cortex and PMG best seen over both fronto-parietal lobes. In central and posterior regions, nearly contiguous periventricular nodular heterotopia were seen with fan-like subcortical heterotopia seen in the same region between the $\mathrm{PNH}$ and microgyric cortex $(\mathrm{H})$.

This article is protected by copyright. All rights reserved. 
Numerous small cavitations were seen in the parietal and occipital white matter (I). Histology of the PNH (arrows, J) confirmed the presence of neurons (arrowheads, J) embedded in neuropil, surrounded by white matter. Histology of the parietal cortex demonstrated mixed PMG and pachygyria (arrows, K), subcortical heterotopia (arrowheads, K), and PNH (asterisks, K).

Figure 4. Clinical photographs and brain imaging from a discordant $M Z$ twin boy (LR12-313a2). The photos $(A-C)$ show multiple congenital contractors including bilateral extended elbows and hyperflexed wrists especially in the left characteristic of amyoplasia. Brain MRI (all volumetric images) show almost all of the cortical and cerebellar malformations described in this series (DL). Large PNH surround the atrium of the right lateral ventricle (arrows in I and $\mathrm{J}$ ) and extend to the right frontal horn, with small PNH adjacent to the left lateral ventricle (F-L). Narrow columns of SUB (sing arrow in $\mathrm{G}$, also seen in $\mathrm{H}$ and $\mathrm{L}$ ) extend from the $\mathrm{PNH}$ up to the overlying cortex, which is irregular consistent with PMG. The cerebellar vermis is small and rotated upward, and the posterior fossa (and cisterns magna) markedly enlarged and meeting criteria for classic DWM (E). The left cerebellar hemisphere is much smaller than the right (bullet in D) with a cleft in the middle cerebellar peduncle (single arrow in $\mathrm{F}, \mathrm{K}$ and $\mathrm{L}$ ).

Figure 5. Clinical photographs, abdominal radiography, and brain imaging from an MZ twin girl (LR18-005). Photos taken in the first few days of life show right clubfoot and a dimple over her left hip (arrow in B). An abdominal radiograph shows abnormal loops of distended bowel distally (asterisks in C), concerning for obstruction. On fluoroscopic upper GI series, contrast does not pass beyond the duodenojejunal junction (double asterisk in D), and subsequent exploratory 
laparotomy confirmed jejunal atresia. Photographs at 2 and 2.5 years show small legs and bilateral clubfeet that have improved with therapy $(E)$, persisting abnormal posture from her leg contractures as well as mild hand contractures $(F)$, and another photos of a dimple over her left hip (G). Brain MRI (T1 sagittal and T2 axial images) show normal midline structures $(H)$, and irregular and unfolded gyral pattern consistent with PMG in bilateral posterior frontal, perisylvian and parietal regions (arrows in I-K) that appears slightly more severe on the left (i.e. right side of the image).

Figure 6. Brain MRI selected for high quality images in 4 individuals with MCD including LR00029 (A-D), LR06-117 (E-H), LR15-063 (I-L) and LR15-136 (M-P). The top row thin corpus callosum (arrow in A), a smaller left hemisphere, asymmetric PMG more severe on the left and in the parieto-occipital regions (arrows in B-D, F-G), narrow open lip cleft on the right (asterisks in $B, D)$, and large open lip cleft on the left (double asterisks in C-D). The second row again shows a smaller left hemisphere and PMG more severe on the left (arrows in F-H), but with no clefts seen. The third row shows a thin corpus callosum that is more severe anteriorly (arrow in I), and extensive PMG that appears more severe on the left (arrows in $\mathrm{J}-\mathrm{L}$, the left brain is on the right side of the image). The bottom row shows bilateral perisylvian PMG that appears more severe and extensive on the left (arrows in N-P).

Figure 7. Brain MRI selected for high quality volumetric images in 2 individuals with MCD including LR18-397 (A-H) and LR18-398 (I-P) that highlight subtle SUB and PNH beneath extensive PMG, which when recognized should increase suspicion for prenatal vascular (e.g.

This article is protected by copyright. All rights reserved. 
non-genetic) cause of the brain malformation. The top two rows show symmetric, bilateral perisylvian PMG (arrows in B-E but also present in F-H) that extends into the frontal lobes and parietal lobes, and small, separated PNH (arrowheads in G) along the walls of the lateral ventricles; these would be missed on low or even standard resolution images. The bottom two rows show bilateral but highly asymmetric PMG, more severe on the right (arrows in J-K), with several small PNH on the right that extend upward as columnar SUB to reach the overlying PMG (arrowheads in J-M and O).

Figure 8. Brain MRI selected to show more diverse patterns of MCD despite low resolution studies in individuals LR02-073a1 (A-D), LR02-073a2 (E-H), LR01-231a1 (I-L) and LR17-510 (M-P). The co-twins in the top two rows both have microcephaly with low, sloping foreheads, extensive PMG (white arrows in A-H) and clefts, but the clefts are widely open in a1 (asterisks in B-D) and closed in a2 (asterisks in F-H). A prominent $\mathrm{PNH}$ is seen in a2 as well (arrowhead in $\mathrm{H}$ ). The next child has extensive PMG (arrows in J-L) surrounding closed lip clefts (asterisks in $\mathrm{J}-\mathrm{L}$ ) associated with a missing middle segment in the body of the corpus callosum (arrow in I). The last child has highly asymmetric PMG more severe on the left (arrow in N-P) without a cleft.

Figure 9. Brain MRI selected to show polymicrogyria (PMG) with deeply infolded heterotopia, parieto-occipital subtype (a.k.a. bilateral parasagittal parietooccipital PMG) in 2 unrelated twins: LP98-090 (A-H) and LR12-429 (I-P). Several gyri and sulci in the occipital lobe fold deeply into the subcortical white matter in the parieto-occipital region (double arrows in $\mathrm{E}$, I and $\mathrm{M}$, single 
arrows in B-D, F-H, K-L, N-P). The infolded heterotopic cortex extends down to and compresses the trigones of the lateral ventricles (arrowheads in $B, F, P$ ).

Figure 10. Brain MRI showing several different cerebellar malformations in subjects LR12-410 (A-D), LR05-398 (E-H), LR12-308 (I-L) and LR12-475 (M-P). The horizontal white lines in A, E, I and $\mathrm{M}$ at the level of the obex mark the usual level of the inferior vermis. The top two rows show diffuse CBLH and the bottom two rows DWM. The top row shows symmetric CBLH in the only surviving triplet born at $25-26$ wkg with a probable cerebellar cleft (arrow in D) on at least one side. The second row shows diffuse $\mathrm{CBLH}$ with mild asymmetry ( $\mathrm{h}$ in $\mathrm{F}$ and $\mathrm{H}$ marks the smaller hemisphere). The bottom two rows show classic DWM with an unpaired caudal lobule or "tail" (arrows in I, M), markedly enlarged cisterna magna (asterisks in I-K, M-N), asymmetric cerebellar hemispheres in one ( $\mathrm{h}$ in $\mathrm{N}$ ) and enlarged and rounded lateral ventricles consistent with hydrocephalus (had in $L$ and $P$ ). The shunt is visible in one child (arrow in $L$ ).

Figure 11. Brain MRI showing different patterns of prenatal brain disruption in subjects LR01355 (A-D), LR07-223 (E-H), LR03-407 (I-L), and LR03-276 (M-P). Serial brain imaging in the MZ twin boy show microcephaly thin mantle (cortex plus white matter on CT scan in B), which progresses to POR (C) and HYDN (D) with progressive ventriculomegaly (* and ** in C-D). The second row shows a DZ twin with POR (asterisks in E, G-H) and an opening from the anterior ventricles to the extra-axial space (arrow in G). The third row shows severe thinning of the corpus callosum (arrow in I), and bilateral posterior POR with very thin white matter (asterisks in J-K). A head CT scan as a newborn showed small ventricles (i.e. no POR yet) and bilateral 
basal ganglia calcifications (arrowhead in L). The last row shows a twin with diffuse, severe loss of white matter volume (arrowheads in N-O) without the cystic appearance of POR. The extra axial space is mildly enlarged (asterisks in $\mathrm{P}$ ).

This article is protected by copyright. All rights reserved. 

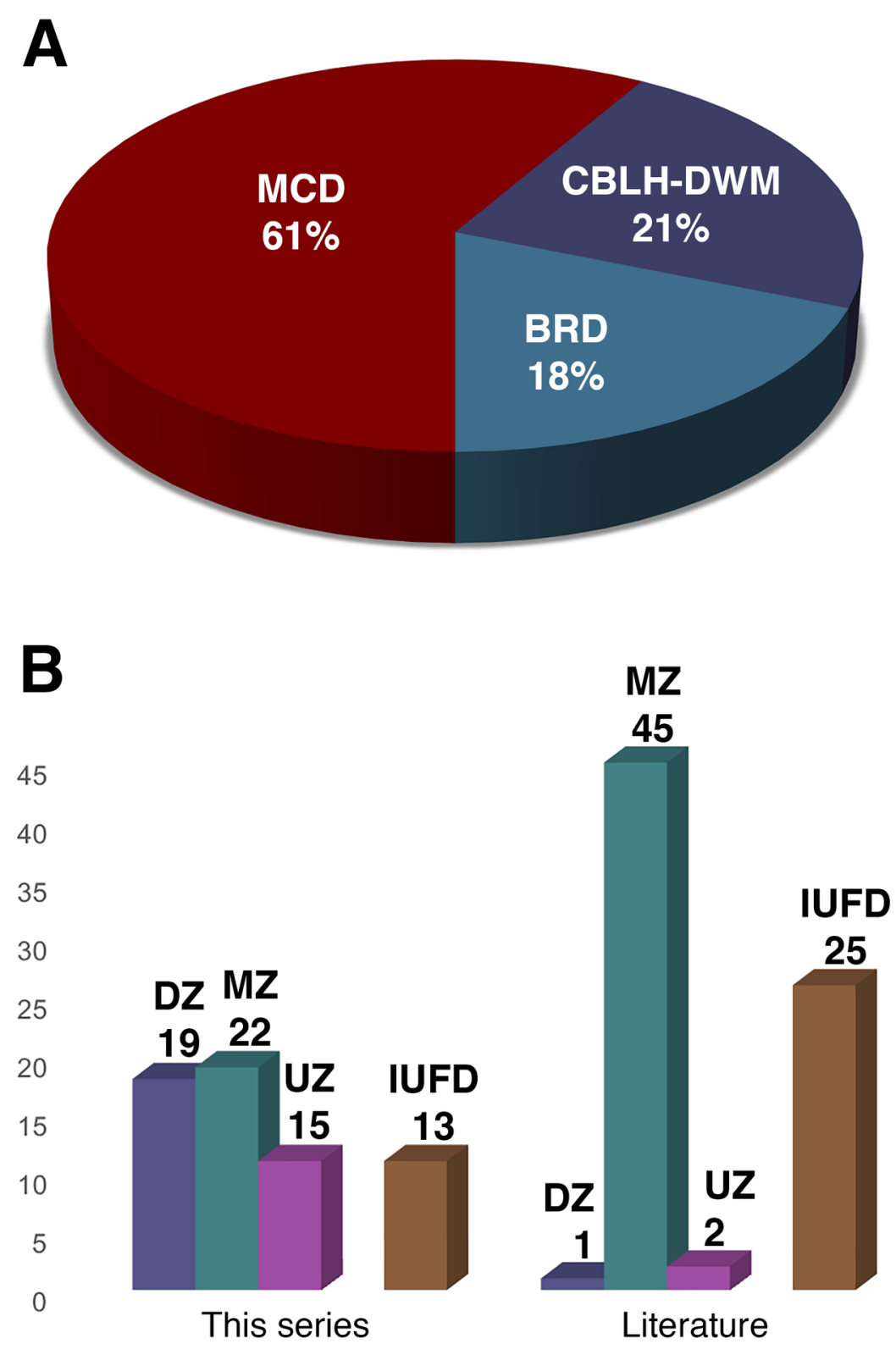

AJMGA_61972_Park MS Twins Fig1v3.tif 

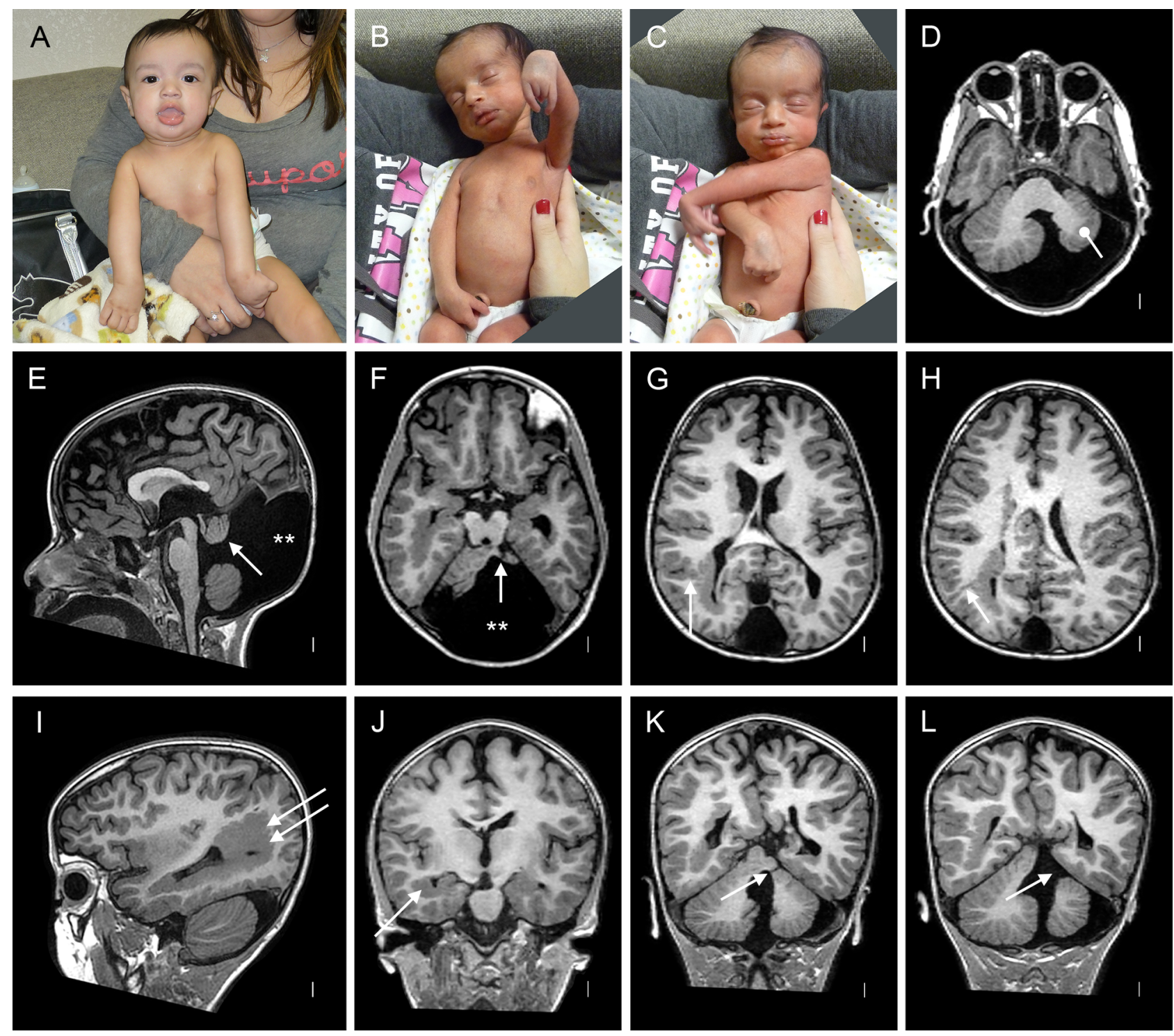

AJMGA_61972_Park MS Twins Fig4v2.tif 

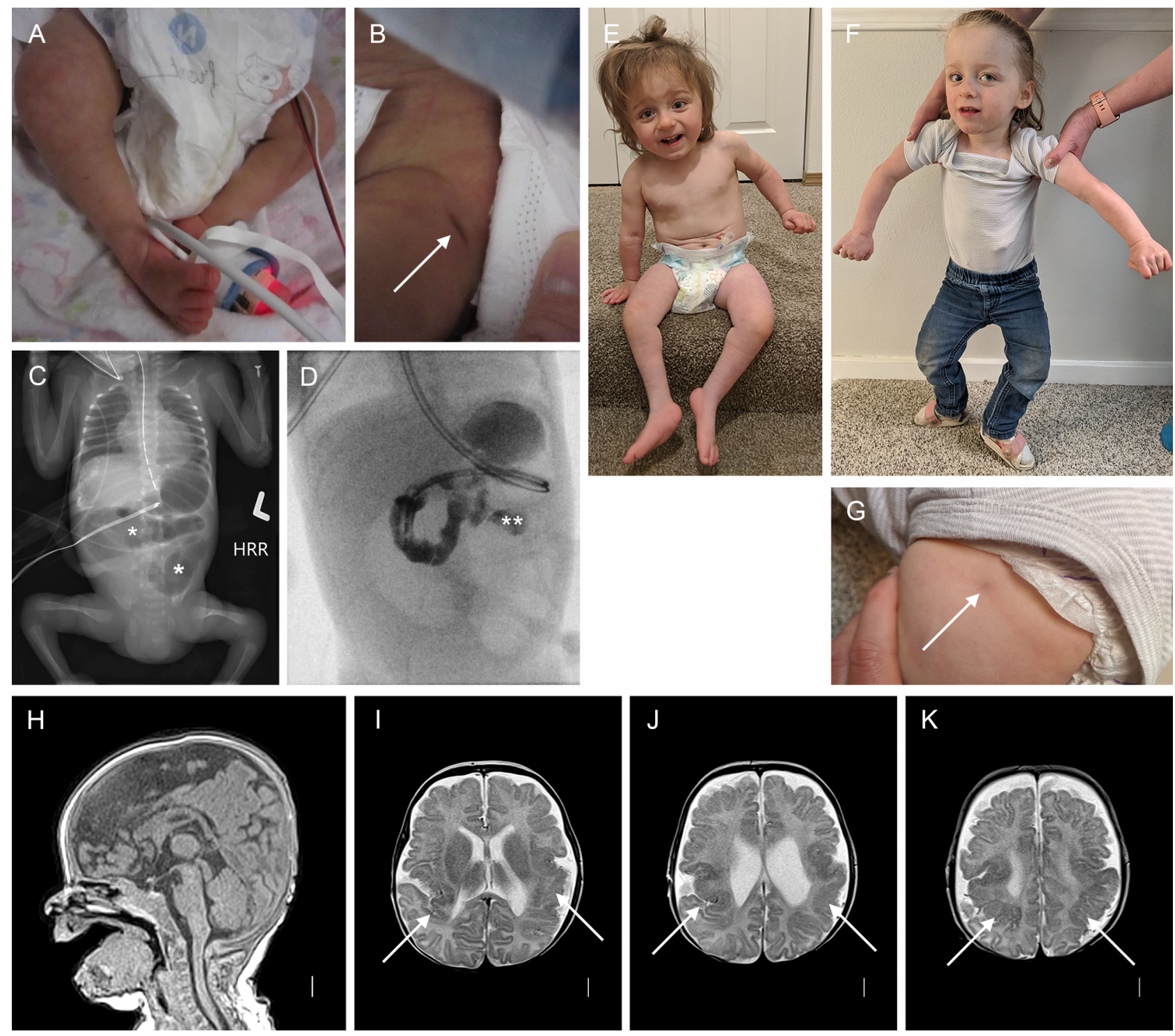

AJMGA_61972_Park MS Twins Fig5v3.tif

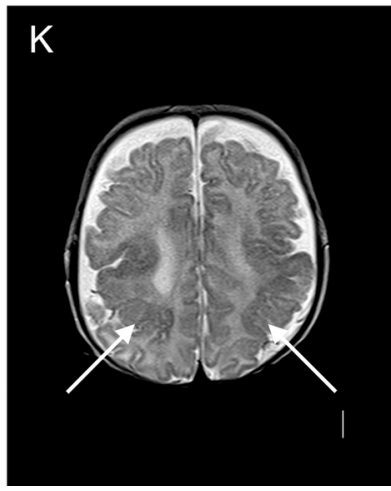

AJMGA_61972_Park MS Twins Fig5v3.tif 

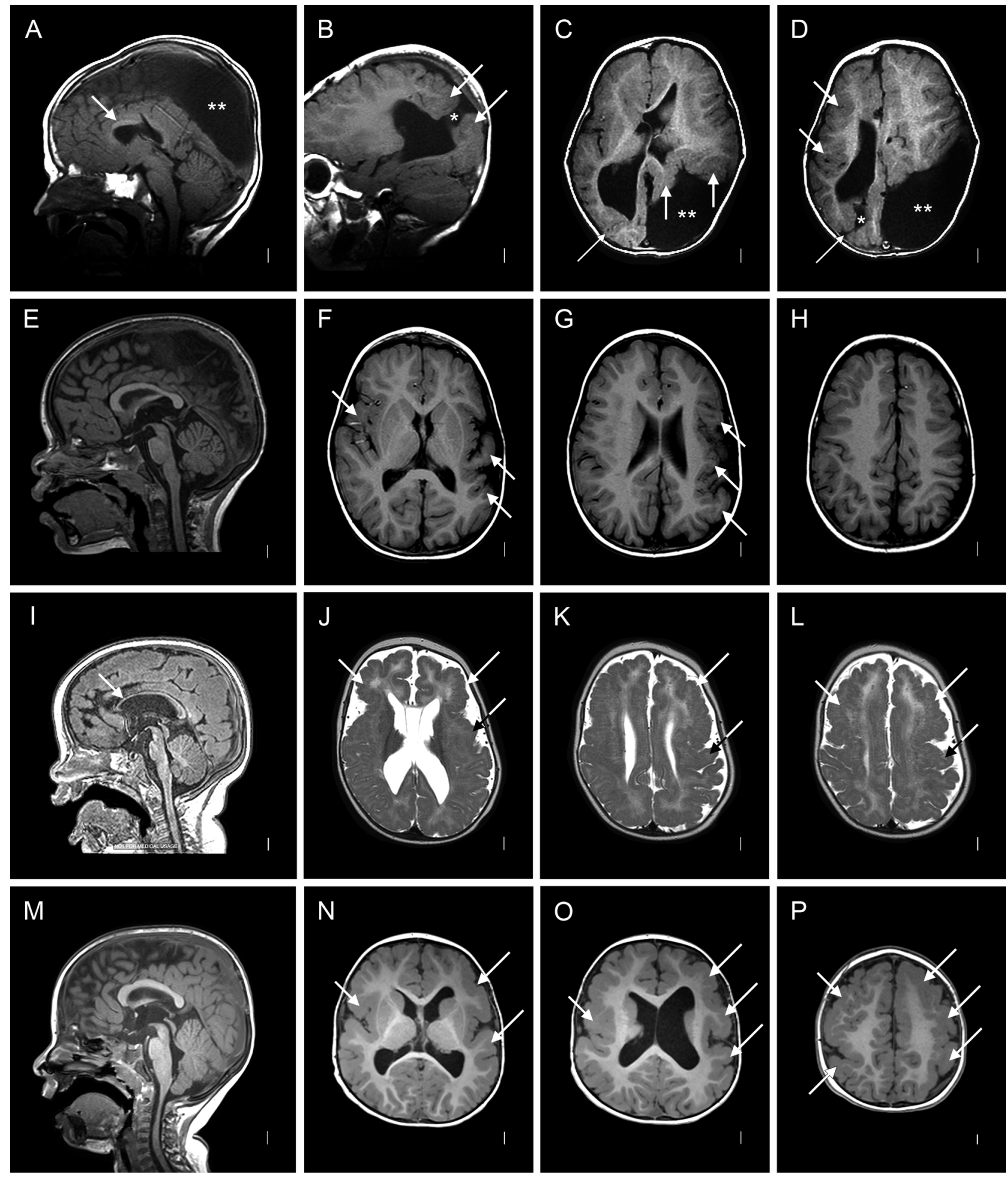

AJMGA_61972_Park MS Twins Fig6v1.tif 

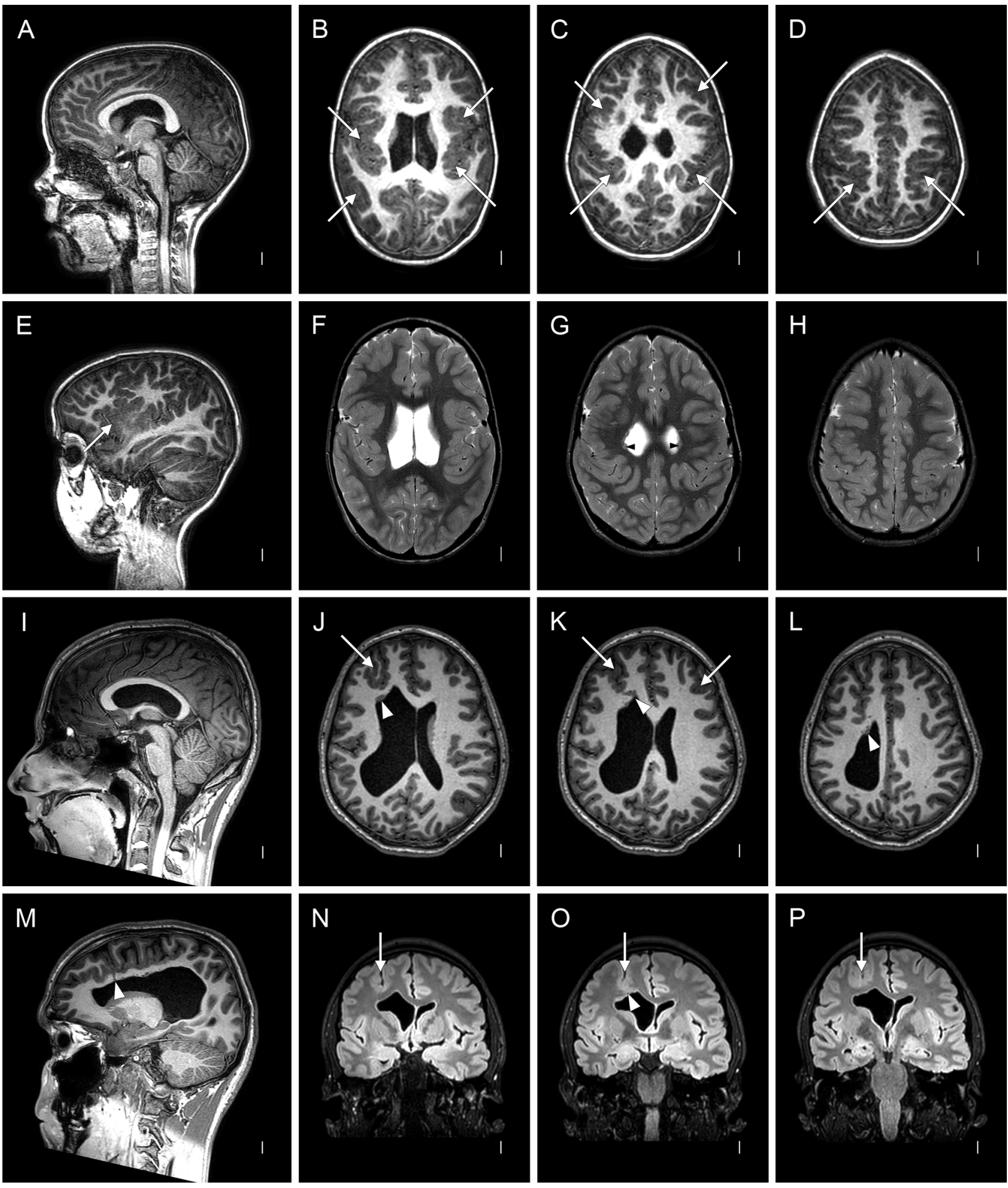

AJMGA_61972_Park MS Twins Fig7v1.tif 

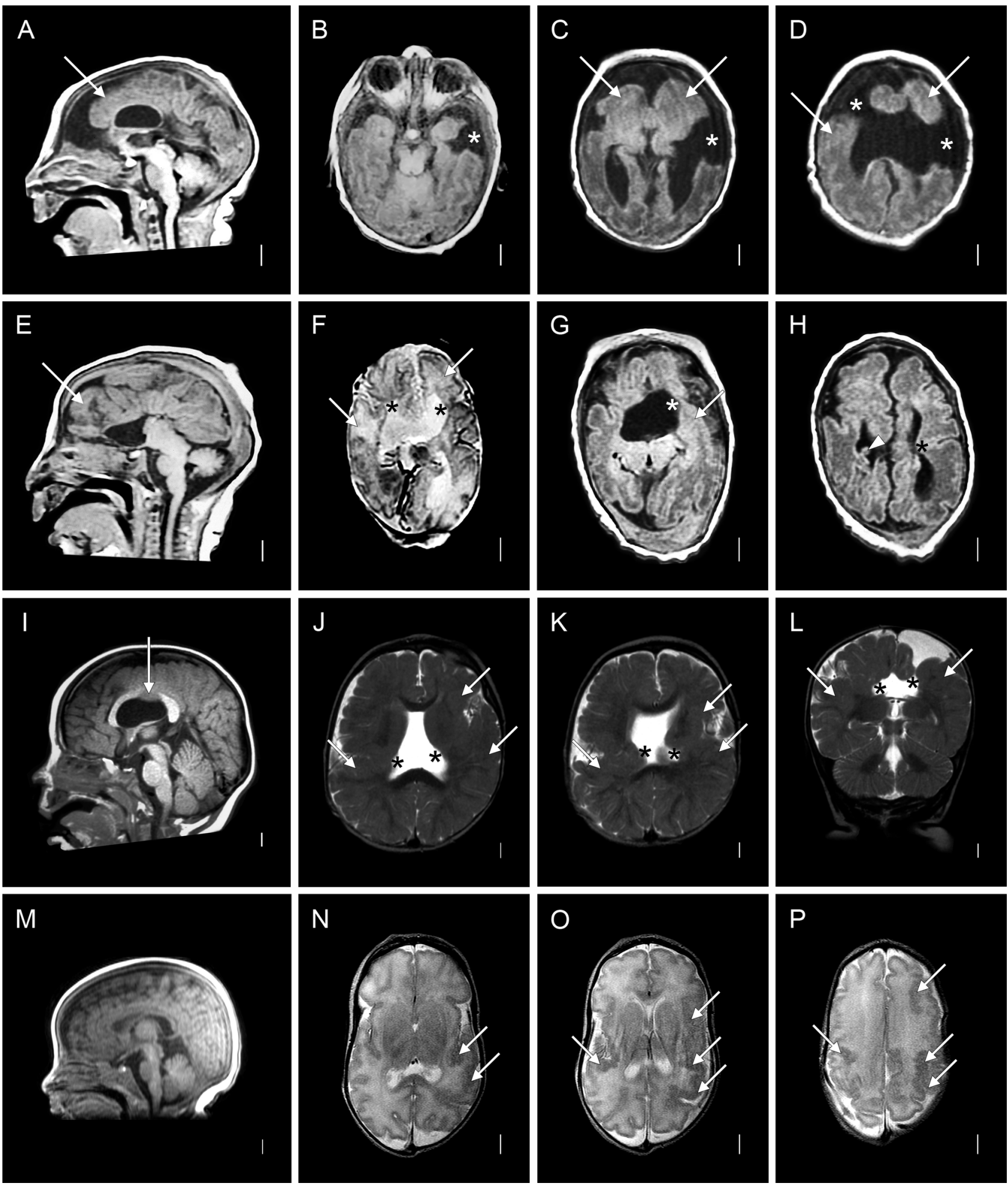

AJMGA_61972_Park MS Twins Fig8v1.tif 

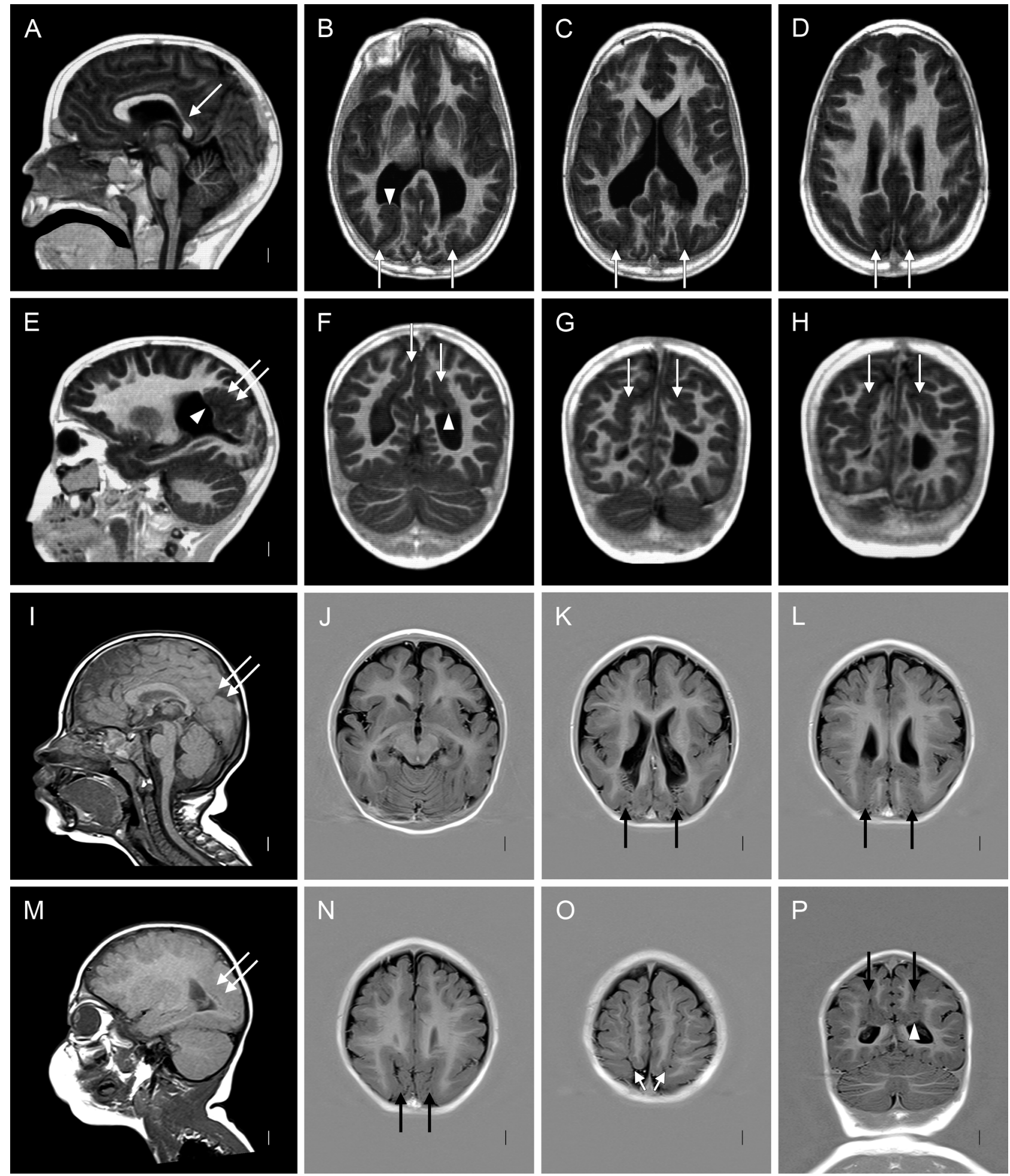

AJMGA_61972_Park MS Twins Fig9v1.tif 

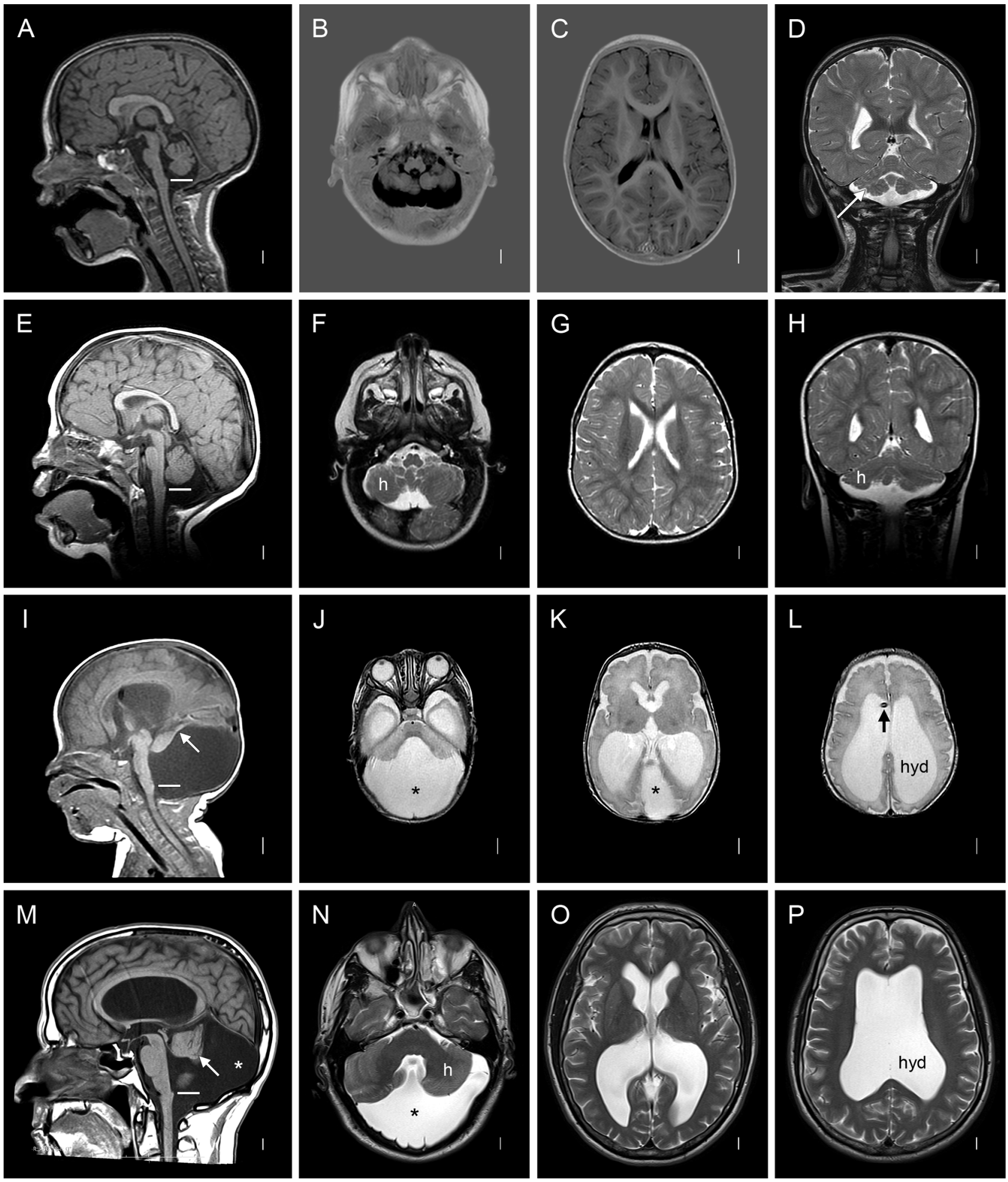

AJMGA_61972_Park MS Twins Fig10v1.tif 

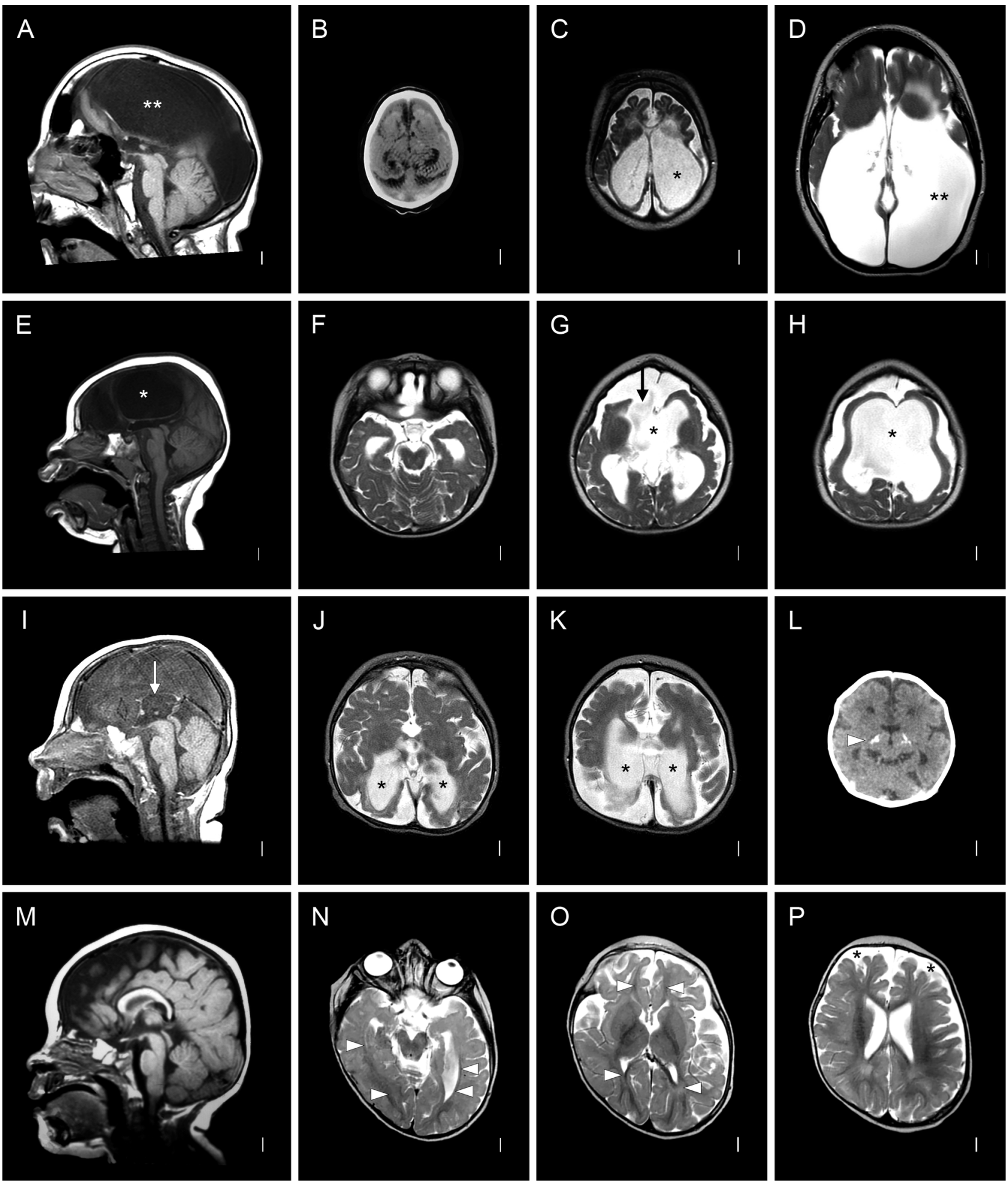

AJMGA_61972_Park MS Twins Fig11v1.tif 

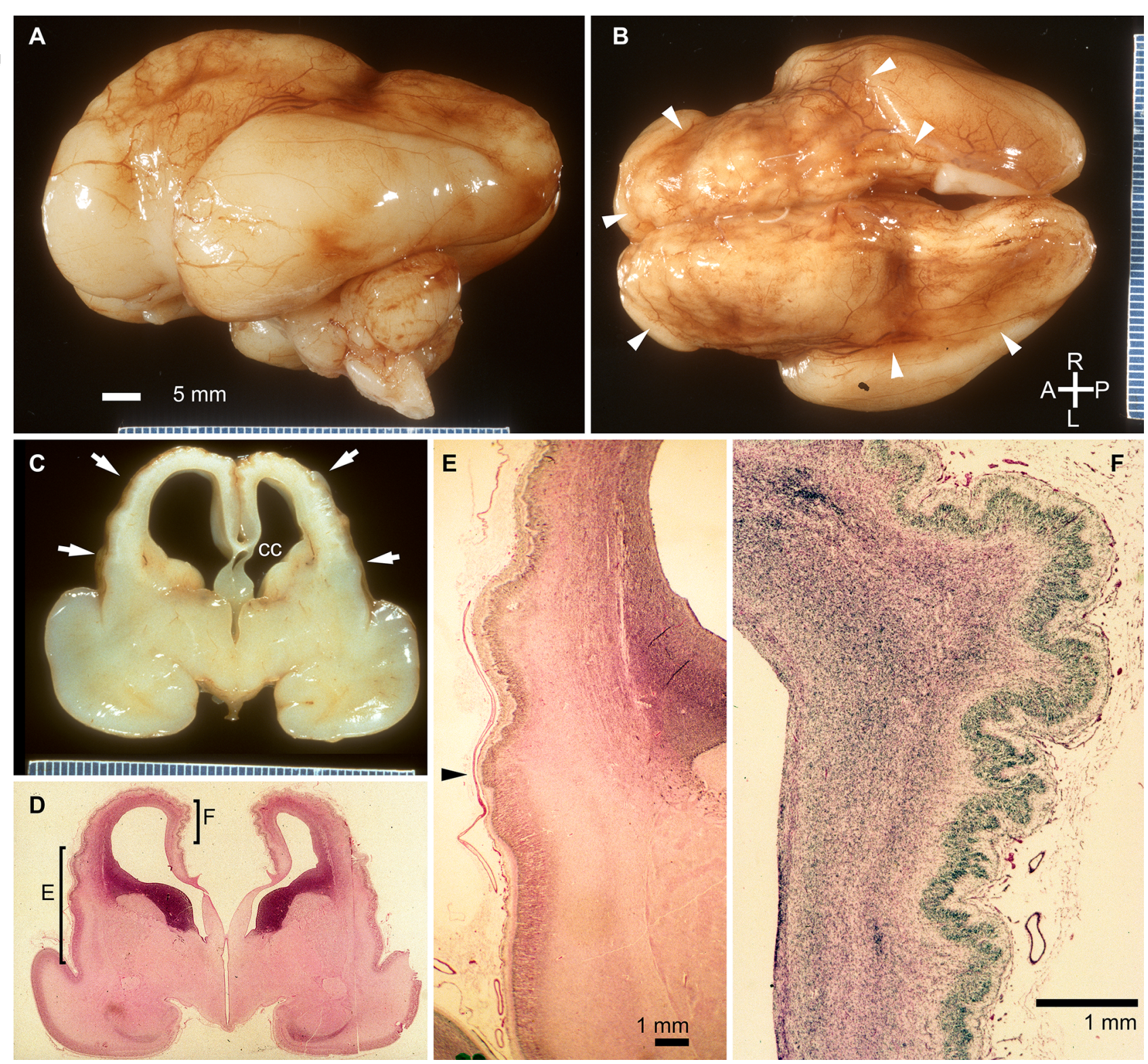

AJMGA_61972_Park MS Twins FIg2v2.tif 

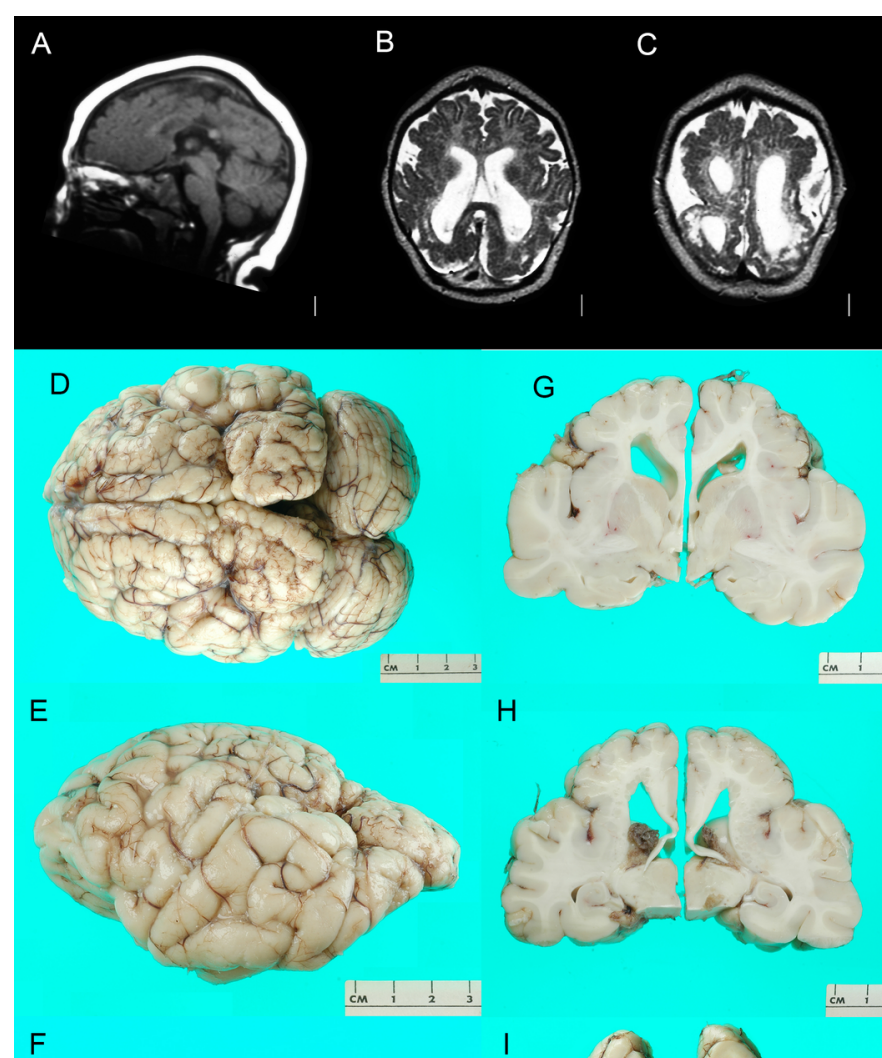

$\mathrm{H}$

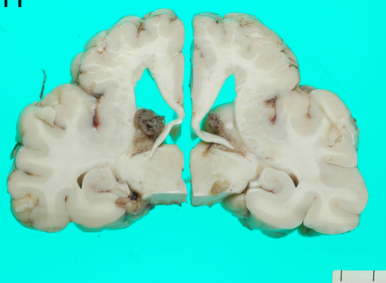

F

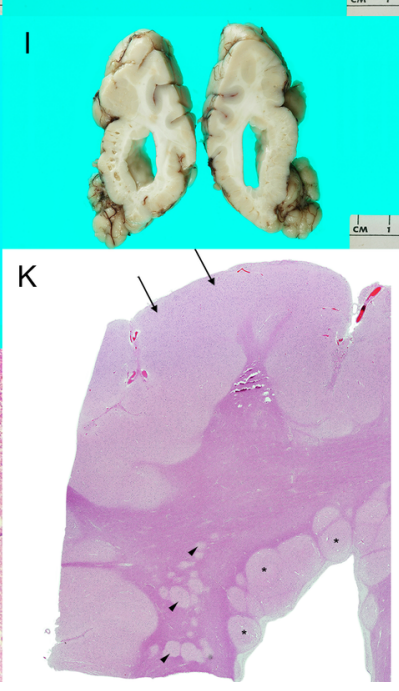

AJMGA_61972_Park MS Twins FIg3v1.tif

This article is protected by copyright. All rights reserved. 
Box 1. List of abbreviations

\begin{tabular}{|l|l|l|l|l|}
\hline ART & artificial reproduction technology & & OAVS & Oculoauriculovertebral Spectrum \\
\hline BRD & brain disruption & & OEIS & $\begin{array}{l}\text { Omphalocele-Exstrophy-Imperforate } \\
\text { Anus-Spinal Defects }\end{array}$ \\
\hline CBLH & cerebellar hypoplasia & & OFC & Occipitofrontal circumference \\
\hline DZ & dizygotic twin & & PMG & polymicrogyria \\
\hline DWM & Dandy-Walker malformation & & PNH & periventricular nodular heterotopia \\
\hline ELGAN & $\begin{array}{l}\text { extremely low gestational age } \\
\text { neonate }\end{array}$ & POC & Pentalogy of Cantrell \\
\hline HYDN & hydranencephaly & POR & porencephaly \\
\hline IUFD & intrauterine fetal demise & SUB & subcortical malformations \\
\hline LBWC & Limb-Body Wall Complex & TTTS & twin-twin transfusion syndrome \\
\hline MZ & monozygotic twin & UZ & unknown zygosity \\
\hline MCD & $\begin{array}{l}\text { malformations of cortical } \\
\text { development }\end{array}$ & VACTERL & $\begin{array}{l}\text { Vertebral-Anal-Cardiac- } \\
\text { Tracheoesophageal Fistula-Renal-Limb } \\
\text { Association }\end{array}$ \\
\hline MURCS & $\begin{array}{l}\text { Mullerian Duct Aplasia-Unilateral } \\
\text { Renal Agenesis-Cervicothoracic } \\
\text { Somite Dysplasia }\end{array}$ & wkg & weeks-gestation \\
\hline
\end{tabular}

This article is protected by copyright. All rights reserved. 
Table 1. Imaging and other features with malformations of cortical development ( $\mathrm{N}=34$ proband twins)

\begin{tabular}{|c|c|c|c|c|c|c|c|c|c|c|c|c|c|}
\hline Subject ID & & & rain in & ging $f$ & atures & & & & & ner fea & ures & & FIGS \\
\hline & PMG & CLEFT $^{6}$ & ASP & SUB & $\mathrm{PNH}$ & ASYM & LAT & ART & Sex & IUFD & ZYG & TTTS & \\
\hline LP93-085a2 & + & - & - & - & - & - & - & & $\mathrm{F}$ & $15-23$ & $\mathrm{MZ}$ & + & 2 \\
\hline LP97-138 & + & + & - & + & + & + & $\mathrm{R}$ & & $\mathrm{F}$ & $16-19$ & DZ & & 3 \\
\hline LP98-0901 & + & - & - & + & + & - & $\mathrm{S}$ & & $\mathrm{F}$ & +7 & UZ & & $9 A-H$ \\
\hline LP99-094 & + & - & - & - & - & - & $\mathrm{S}$ & & $\mathrm{M}$ & - & $M Z$ & & \\
\hline LR00-029 & + & + & - & + & + & + & $L$ & & $M$ & $6-10$ & UZ & & $6 A-D$ \\
\hline LR01-029 & + & + & - & - & + & - & $\mathrm{S}$ & IVF & $M$ & 16 & $\mathrm{MZ}$ & + & \\
\hline LR01-231a1 & + & + & + & - & - & + & $\mathrm{R}$ & & $M$ & & UZ & & $8 \mathrm{II}-\mathrm{L}$ \\
\hline LR01-283a11 & + & - & - & + & + & - & $\mathrm{S}$ & & $\mathrm{F}$ & & $\mathrm{MZ}$ & & \\
\hline LR02-073a2 & + & + & + & - & - & + & $\mathrm{R}$ & & $M$ & & UZ & & $8 E-H$ \\
\hline LR02-315a1 & + & - & - & - & - & + & $\mathrm{R}$ & & $\mathrm{M}$ & & $\mathrm{DZ}$ & & \\
\hline LR04-110 & + & - & - & - & - & + & L & & $\mathrm{F}$ & 20 & UZ & & \\
\hline LR06-117² & + & - & - & - & - & + & $\mathrm{L}$ & & $M$ & $<24$ & UZ & + & $6 E-H$ \\
\hline LR07-038a1 & + & - & - & - & - & - & $\mathrm{S}$ & & $\mathrm{F}$ & & $\mathrm{MZ}$ & & \\
\hline LR09-420a2* & + & - & - & - & - & + & $L$ & IVF & $\mathrm{M}$ & & DZ & & \\
\hline LR10-042* & + & - & - & - & - & + & $\mathrm{L}$ & & $\mathrm{F}$ & $19-20$ & UZ & + & \\
\hline LR10-101* & + & - & + & + & + & + & $L$ & IVF & $M$ & & DZ & & \\
\hline LR12-155 & + & - & - & - & - & - & $\mathrm{S}$ & & $\mathrm{F}$ & & $\mathrm{DZ}$ & & \\
\hline LR12-313a23* & + & - & - & + & + & + & $\mathrm{R}$ & & $M$ & & $\mathrm{MZ}$ & & 4 \\
\hline LR12-4291 & + & - & - & + & + & + & $\mathrm{R}$ & & $\mathrm{M}$ & +7 & UZ & & 91-P \\
\hline LR13-240a2 & + & - & - & - & - & - & $S$ & & $\mathrm{~F}$ & - & $\mathrm{MZ}$ & & \\
\hline LR15-063 & + & - & - & + & - & - & $\mathrm{S}$ & & $\mathrm{M}$ & & $\mathrm{DZ}$ & & $6 \mathrm{GI}-\mathrm{L}$ \\
\hline LR15-136 & + & - & - & - & - & + & $\mathrm{R}$ & & $M$ & & $M Z$ & & $6 \mathrm{M}-\mathrm{P}$ \\
\hline LR17-510 & + & - & - & - & - & - & $\mathrm{S}$ & & $\mathrm{F}$ & & $\mathrm{MZ}$ & & $8 \mathrm{M}-\mathrm{P}$ \\
\hline LR18-0053 & + & + & - & - & - & + & $\mathrm{R}$ & & $\mathrm{F}$ & & $\mathrm{MZ}$ & + & 5 \\
\hline LR18-39733 & + & - & - & - & + & + & $\mathrm{R}$ & & $M$ & & $M Z$ & & $7 \mathrm{~A}-\mathrm{H}$ \\
\hline LR18-398 & + & - & - & + & + & + & $\mathrm{R}$ & & $M$ & & $\mathrm{MZ}$ & & 7II-P \\
\hline LR20-004a1 & + & + & - & - & - & + & $L$ & & $\mathrm{~F}$ & & $M Z^{*}$ & & \\
\hline LR20-043 & + & - & + & - & + & - & $\mathrm{S}$ & & $\mathrm{F}$ & & $\mathrm{DZ}$ & & \\
\hline LR20-090 & - & - & - & - & + & - & $\mathrm{S}$ & & $\mathrm{F}$ & & $\mathrm{MZ}$ & & \\
\hline LR20-0914 & - & - & - & + & + & - & $\mathrm{S}$ & & $F$ & & $\mathrm{MZ}$ & & \\
\hline LR20-0921 & + & - & - & + & - & + & $\mathrm{L}$ & & $\mathrm{F}$ & & $\mathrm{MZ}$ & & \\
\hline LR20-093 & + & - & - & - & - & - & $\mathrm{S}$ & & $M$ & 17 & UZ & & \\
\hline LR20-094 & + & - & - & - & - & + & $\mathrm{R}$ & & $M$ & & $\mathrm{MZ}$ & +8 & \\
\hline LR20-095 & + & - & - & - & - & + & $\mathrm{R}$ & & $\mathrm{M}$ & & DZ & & \\
\hline PROBANDS & 32 & 7 & 4 & 11 & 13 & 20 & & & $18 \mathrm{M} / 16 \mathrm{~F}$ & $\mathrm{~N}=10$ & 8DZ-1 & Z-9UZ & \\
\hline
\end{tabular}

This article is protected by copyright. All rights reserved. 


\begin{tabular}{|c|c|c|c|c|c|c|c|c|c|c|c|c|c|}
\hline \multirow[t]{2}{*}{ Subject ID } & \multicolumn{7}{|c|}{ Brain imaging features } & \multicolumn{5}{|c|}{ Other features } & \multirow[t]{2}{*}{ FIGS } \\
\hline & PMG & CLEFT $^{6}$ & ASP & SUB & $\mathrm{PNH}$ & ASYM & LAT & ART & Sex & IUFD & ZYG & TTTS & \\
\hline \multicolumn{14}{|l|}{ Affected sibs } \\
\hline LR01-283a21,5 & + & - & - & + & + & - & $\mathrm{S}$ & & $\mathrm{F}$ & & $\mathrm{MZ}$ & & \\
\hline LR02-073a1 & + & + & + & - & - & + & $\mathrm{L}$ & & $\mathrm{M}$ & & UZ & & 8A-D \\
\hline LR09-420a1* & + & - & - & - & - & + & $\mathrm{R}$ & IVF & $\mathrm{F}$ & & DZ & & \\
\hline LR13-240a1 & + & - & - & - & - & - & $\mathrm{S}$ & & $\mathrm{F}$ & - & $\mathrm{MZ}$ & & \\
\hline LR20-004a2 & + & - & - & - & + & + & $\mathrm{L}$ & & $\mathrm{F}$ & & $\mathrm{MZ}$ & & \\
\hline TOTAL & 37 & 8 & 5 & 12 & 15 & 23 & & & & 10 & & & \\
\hline
\end{tabular}

Abbreviations: ART, artificial reproductive technology; ASP, absent septum pellucidum; ASYM, asymmetry of hemisphere size and/or cortical malformation; CLEFT, gray matter lined pia-ependymal cleft as seen in schizencephaly; DZ, dizygotic; F, female; FIGS, figures; IUFD, intrauterine fetal demise in weeks gestation; IVF, in vitro fertilization; L, more severe on left; LAT, laterality; M, male; MZ, monozygotic; PMG, polymicrogyria; PNH, periventricular nodular heterotopia; R, more severe on right; S, symmetric; SUB, subcortical malformation including heterotopia; TTTS, twin-twin transfusion syndrome; UZ, unknown zygosity; ZYG, zygosity. Notes: ${ }^{1}$ SUB and PNH are deeply infolded heterotopia, parieto-occipital subtype a.k.a. bilateral parasagittal parietooccipital PMG; ${ }^{2}$ This child was born at 24 weeks gestation (ELGAN). ${ }^{3}$ These children have arthrogryposis multiplex congenita (3-limb amyoplasia pattern in LR12-313a2); ${ }^{4}$ The SUB seen in this child were thin almost threadlike columns sometimes intertwined with long perivascular spaces, although some could represent long perivascular spaces; ${ }^{5}$ This woman has moderate cerebellar atrophy as well, but was treated with high dose phenytoin for many years; ${ }^{6}$ This group includes clefts in cerebral hemispheres only, not the cerebellum. ${ }^{7}$ Timing of IUFD not reported. ${ }^{8}$ Reported as twin anemia polycythemia sequence or TAPS. *Also included in Table 2 as subjects have both MCD and cerebellar malformations.

This article is protected by copyright. All rights reserved. 
Table 2. Imaging and other features with cerebellar malformations ( $\mathrm{N}=12$ proband twins)

\begin{tabular}{|c|c|c|c|c|c|c|c|c|c|c|c|c|}
\hline \multirow[t]{2}{*}{ Subject ID } & \multicolumn{6}{|c|}{ Brain imaging features } & \multicolumn{5}{|c|}{ Other features } & \multirow[t]{2}{*}{ FIGS } \\
\hline & DWM & $\mathrm{CBLH}^{1}$ & CLEFT $^{2}$ & ASYM & $\mathrm{BSH}$ & LAT & ART & Sex & IUFD & $Z Y G^{3}$ & TTTS & \\
\hline \multicolumn{13}{|l|}{ CBLH only } \\
\hline LR03-0555 & - & + & - & + & - & $\mathrm{R}$ & & $\mathrm{M}$ & - & $\mathrm{DZ}$ & & \\
\hline LR03-278 & + & - & - & - & - & $\mathrm{S}$ & & $\mathrm{M}$ & - & UZ & & \\
\hline LR03-298 & + & - & - & - & - & $\mathrm{S}$ & & $\mathrm{M}$ & - & $\mathrm{MZ}$ & & \\
\hline LR04-239 & - & + & - & - & + & $\mathrm{R}$ & & $M$ & - & $\mathrm{DZ}$ & & \\
\hline LR05-035 & + & - & - & + & - & $\mathrm{S}$ & & $\mathrm{M}$ & - & $\mathrm{MZ}$ & + & \\
\hline LR05-398 & - & + & - & - & - & $\mathrm{S}$ & & $\mathrm{M}$ & - & $\mathrm{MZ}$ & + & $10 \mathrm{E}-\mathrm{H}$ \\
\hline LR12-032 & - & + & - & - & - & $\mathrm{S}$ & & $\mathrm{F}$ & - & $\mathrm{DZ}$ & & \\
\hline LR12-308 & + & - & - & + & - & $\mathrm{L}$ & & $\mathrm{F}$ & - & $\mathrm{MZ}$ & + & $10 \mathrm{I}-\mathrm{L}$ \\
\hline LR12-410 4 & - & + & + & - & - & $\mathrm{S}$ & IVF & $\mathrm{M}$ & - & $\mathrm{UZ}$ & & 10A-D \\
\hline LR12-475 & + & - & - & + & - & $\mathrm{L}$ & & $M$ & - & $\mathrm{DZ}$ & & $10 \mathrm{M}-\mathrm{P}$ \\
\hline LR14-098 & + & - & - & - & - & $\mathrm{S}$ & IVF & $\mathrm{F}$ & - & $\mathrm{DZ}$ & & \\
\hline LR18-080 & - & + & - & - & - & $\mathrm{S}$ & IVF & $\mathrm{F}$ & - & $\mathrm{DZ}$ & - & \\
\hline PROBANDS & 6 & 6 & 1 & 4 & 1 & & & $8 \mathrm{M} / 4 \mathrm{~F}$ & 0 & \multicolumn{2}{|c|}{ 6DZ-4MZ-2UZ } & \\
\hline \multirow{2}{*}{\multicolumn{13}{|c|}{ Affected sib }} \\
\hline & & & & & & & & & & & & \\
\hline LR14-018a2 & - & + & - & - & - & $\mathrm{S}$ & IVF & $\mathrm{M}$ & - & DZ & & \\
\hline & & & & & & & & & & & & \\
\hline \multicolumn{13}{|c|}{ MCD+CBLH from Table 1} \\
\hline LR09-420a1* & - & + & - & - & - & $\mathrm{R}$ & & $\mathrm{F}$ & - & $\mathrm{DZ}$ & & \\
\hline LR09-420a2* & - & + & - & + & - & $\mathrm{L}$ & & $\mathrm{M}$ & - & $\mathrm{DZ}$ & & \\
\hline LR10-042* & - & + & - & - & - & $\mathrm{S}$ & & $\mathrm{F}$ & - & $\mathrm{UZ}$ & & \\
\hline LR10-101* & - & + & - & + & - & $\mathrm{L}$ & & $\mathrm{M}$ & - & $\mathrm{DZ}$ & & \\
\hline LR12-313a2* & + & - & - & + & - & $\mathrm{R}$ & & $M$ & - & $\mathrm{MZ}$ & & \\
\hline LR20-095* & & + & 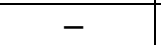 & $\begin{array}{lll}- \\
\end{array}$ & - & $\mathrm{S}$ & & $\mathrm{M}$ & - & $\mathrm{DZ}$ & & \\
\hline TOTAL & 7 & 12 & 1 & 7 & 1 & & & & 0 & & & \\
\hline \multicolumn{13}{|c|}{$\begin{array}{l}\text { Abbreviations: ART, artificial reproductive technology; ASYM, asymmetry of cerebellar hemispheres; BSH, brainstem } \\
\text { hypoplasia; CBLH, cerebellar hypoplasia; CLEFT, cleft in cerebellum from surface to central white matter; DWM, Dandy-Walker } \\
\text { malformation; DZ, dizygotic; F, female; FIGS, figures; IUFD, intrauterine fetal demise; IVF, in vitro fertilization; L, more severe on } \\
\text { left; LAT, laterality; M, male; MZ, monozygotic; R, more severe on right; S, symmetric; TTTS, twin-twin transfusion syndrome; } \\
\text { UZ, unknown zygosity; ZYG, zygosity. Notes: }{ }^{1} \text { CBLH includes diffuse CBLH, vermis predominant CBLH, and CBLH with mega- } \\
\text { cisterna magna. }{ }^{2} \text { This group refers only to cerebellar clefts. }{ }^{3} \text { Zygosity: } 6 D Z-5 M Z-1 U Z \text {. }{ }^{4} \text { Only surviving triplet born at } 25-26 \text { wkg } \\
\text { (ELGAN). }{ }^{5} \text { Born at } 22.5 \text { wkg (ELGAN), another potential cause of the CBLH. }{ }^{*} \text { Twins with malformations of cortical development } \\
\text { (MCD) and cerebellar malformations were included as probands or sibs in Table } 1 \text {. }\end{array}$} \\
\hline
\end{tabular}

This article is protected by copyright. All rights reserved. 
Table 3. Imaging and other features with brain disruptions ( $\mathrm{N}=10$ proband twins)

\begin{tabular}{|c|c|c|c|c|c|c|c|c|c|c|c|c|}
\hline Subject ID & \multicolumn{6}{|c|}{ Brain imaging features } & \multicolumn{5}{|c|}{ Other features } & \multirow[t]{2}{*}{ FIGS } \\
\hline & WM loss & HYDN & POR & VMEG & ASYM & LAT & ART & SEX & IUFD & ZYG & TTTS & \\
\hline LR01-355 & + & + & - & + & - & $\mathrm{S}$ & & $M$ & $18-25$ & UZ & & $11 \mathrm{~A}-\mathrm{D}$ \\
\hline LR03-229 & + & + & - & + & - & $\mathrm{S}$ & & $\mathrm{F}$ & 18 & $\mathrm{MZ}$ & & \\
\hline LR03-276 & + & - & - & - & - & $\mathrm{S}$ & & $M$ & & $\mathrm{DZ}$ & & $11 \mathrm{M}-\mathrm{P}$ \\
\hline LR03-380 & + & - & + & + & + & $\mathrm{R}$ & & $\mathrm{F}$ & & UZ & & \\
\hline LR03-407 & + & - & + & + & - & $\mathrm{S}$ & & $\mathrm{F}$ & 14 & UZ & & $11 I-L$ \\
\hline LR07-223 & + & - & + & + & - & $\mathrm{S}$ & & $M$ & & $\mathrm{DZ}$ & & $11 \mathrm{E}-\mathrm{H}$ \\
\hline LR09-422 & + & - & - & - & - & $\mathrm{S}$ & & $\mathrm{F}$ & & UZ & & \\
\hline LR11-173 & + & - & - & + & - & $\mathrm{S}$ & & $\mathrm{F}$ & - & $\mathrm{DZ}$ & & \\
\hline LR11-243 & + & - & - & - & - & $\mathrm{S}$ & IVF & $\mathrm{M}$ & & $\mathrm{DZ}$ & & \\
\hline LR14-018a1 & + & - & - & +1 & - & $\mathrm{S}$ & & $M$ & - & $\mathrm{DZ}$ & & \\
\hline PROBANDS & 10 & 2 & 3 & 7 & 1 & & & $5 \mathrm{M} / 5 \mathrm{~F}$ & 3 & 5DZ-1I & $-4 U Z$ & \\
\hline \multicolumn{13}{|l|}{ Affected sib } \\
\hline LR07-038a2 & + & - & - & + & - & $\mathrm{S}$ & & $\mathrm{F}$ & & $\mathrm{MZ}$ & & \\
\hline TOTAL & 11 & 2 & 3 & 8 & 1 & & & & 3 & & & \\
\hline \multicolumn{13}{|c|}{$\begin{array}{l}\text { Abbreviations: ART, artificial reproductive technology; ASYM, asymmetry of brain disruption; DZ, dizygotic; F, female; FIGS, } \\
\text { figures; HYDN, hydranencephaly; IUFD, intrauterine fetal demise in weeks gestation; IVF, in vitro fertilization; LAT, laterality; M, } \\
\text { male; MZ, monozygotic; POR, porencephaly; R, more severe on right; S, symmetric; TTTS, twin-twin transfusion syndrome; UZ, } \\
\text { unknown zygosity; VMEG, ventriculomegaly; WM loss, white matter volume loss; ZYG, zygosity. Notes: }{ }^{1} \text { hydrocephalus with } \\
\text { ventriculo-peritoneal shunt. }\end{array}$} \\
\hline
\end{tabular}

This article is protected by copyright. All rights reserved. 
Table 4. Associated malformations and disruptions in twins in this series and reports

\begin{tabular}{|c|c|c|c|c|c|}
\hline Subject & MCD & DWM & ZYG & IUFD & Associated malformations / disruptions \\
\hline LP97-138 & PMG-SUB-PNH & & DZ & + & Optic nerve hypoplasia, panhypopituitarism \\
\hline LP98-090 & PMG-SUB-PNH & & $\mathrm{UZ}$ & + & Congenital cutis aplasia of scalp \\
\hline LR00-029 & PMG-SUB-PNH & & UZ & + & Bilateral clubfeet \\
\hline LR03-380 & None (group 3) & & UZ & & Amniotic band disruption sequence ${ }^{1}$ \\
\hline LR07-038a1 & PMG & & $\mathrm{MZ}$ & & Vocal cord paralysis ${ }^{2}$ \\
\hline LR12-313a2 & PMG-SUB-PNH & DWM & $\mathrm{MZ}$ & & Amyoplasia (3-limb, see text) \\
\hline LR17-510 & PMG & & MZ & & Vocal cord paralysis ${ }^{2}$ \\
\hline LR18-005 & PMG & & $\mathrm{MZ}$ & & Jejunal atresia, leg contractures, clubfeet \\
\hline LR18-397 & PMG-PNH & & $\mathrm{MZ}$ & & Arthrogryposis multiplex congenita ${ }^{3}$ \\
\hline Baker 1996 & PMG-SUB-PNH & & MZ & + & Congenital contractures, not defined \\
\hline Malinowski & & DWM & & + & Gastroschisis (limited details provided) \\
\hline Mochizuki & PMG & & $\mathrm{MZ}$ & + & Multiple intestinal atresias (at 13 sites) \\
\hline Shue 2012 & PMG & & $\mathrm{MZ}$ & + & Multiple intestinal atresias (at 8 sites) \\
\hline \multicolumn{6}{|c|}{$\begin{array}{l}\text { Note: }{ }^{1} \text { Features included unilateral right anopthalmia with surrounding alopecia, cleft lip and soft palate, } \\
\text { multiple constriction bands, multiple shortened fingers and toes; }{ }^{2} \text { we have observed polymicrogyria with } \\
\text { vocal cord paralysis in several singletons as well. }{ }^{3} \text { Oropharynx, hands and feet most severe, unable to } \\
\text { open his mouth. }\end{array}$} \\
\hline
\end{tabular}

Table 5. Sex and zygosity for discordant twins in this series and literature series

\begin{tabular}{|c|c|c|c|c|c|c|c|}
\hline & $\mathbf{N}$ & \multicolumn{3}{|c|}{ Sex } & \multicolumn{3}{|c|}{ Zygosity } \\
\hline This series & & $M$ & $\mathrm{~F}$ & UNK & $\mathrm{DZ}$ & $\mathrm{MZ}$ & UZ \\
\hline MCD & 34 & 18 & 16 & 0 & 8 & 17 & 9 \\
\hline CBLH-DWM & 12 & 8 & 4 & 0 & 6 & 4 & 2 \\
\hline BRD & 10 & 5 & 5 & 0 & 5 & 1 & 4 \\
\hline TOTAL & 56 & 31 & 25 & 0 & 19 & 22 & 15 \\
\hline & $\mathbf{N}$ & & Sex & & & gos & \\
\hline Literature series & & $M$ & $\mathrm{~F}$ & UNK & $\mathrm{DZ}$ & $\mathrm{MZ}$ & UZ \\
\hline MCD & 14 & 7 & 7 & 0 & 0 & 14 & 0 \\
\hline CBLH-DWM & 16 & 3 & 6 & 7 & 0 & 14 & 2 \\
\hline BRD & 18 & 14 & 4 & 0 & 1 & 17 & 0 \\
\hline TOTAL & 48 & 24 & 17 & 7 & 1 & 45 & 2 \\
\hline
\end{tabular}

Abbreviations: BRD, brain disruptions including hydranencephaly-porencephaly; $\mathrm{CBLH}$, cerebellar hypoplasia; DWM, Dandy-Walker malformation; DZ, dizygotic twins; MCD, malformation of cortical development; MZ, monozygotic twins; UNK, unknown sex; UZ, unknown zygosity. $\mathrm{N}=43$ subjects with 3 affected co-twins excluded. References for Literature twin cohort provided in Supplementary Tables 2-4. For 7/56 proband twins, the co-twin was concordant for a brain malformation or disruption, but discordant for severity; the more severely affected co-twin was always selected as the proband twin. 
